\title{
Industrial Transformation with Heterogeneous Labour and Foreign Experts
}

\author{
King Yoong Lim* \\ Lancaster University Management School
}

January 4, 2018

\begin{abstract}
This paper develops an endogenous growth model with industrial transformation and a stylised foreign expert-based 'internalisation advantage' framework to determine the composition of heterogeneous foreign multinationals in a developing host economy. A key feature of the model is the introduction of a dichotomous relationship between domestic and foreign firms, where the latter perceives heterogeneity among the productivity of domestic workers. This results in the skills acquisition decision and foreign subsidiaries' operational mode choice to be determined along the same ability distribution of the host economy. This subsequently determines the shares of the different types of multinationals in a host economy. Parameterised for Malaysia, policy experiments are conducted. A balanced investment liberalisation measure for all foreign firms is found to outperform measure targeting only selected types, though there is a threshold doing-business cost value below which such a standalone FDI-promoting policy does not generate positive growth effect. This then calls for composite programme that maximises the policy complementarities between human capital and FDI-promoting policies.
\end{abstract}

JEL Classification Numbers: F23, O14, O33, O41.

Keywords: Foreign Experts, Human Capital, Industrial Transformation, Innovation.

*Address: Room 67a, Economics Department, Lancaster University Management School, Bailrigg Lancaster LA1 4YX, United Kingdom. E-mail address: k.y.lim3@lancaster.ac.uk. I would like to thank Pierre-Richard Agénor for his dedicated supervision and helpful feedback. I am also grateful to Christoph Himmels, Kyriakos Neanidis, Timo Trimborn, the Editors and reviewers for their invaluable feedback, which have contributed to the improvement of this article. I bear sole responsibility for the views expressed in this paper. Appendices are made available upon request. 


\section{Introduction}

Ever since Saggi (2002) documented the scarcity of studies modelling the relative importance of the different types of Foreign Direct Investment (FDI) in the industrial transformation process of developing economies, this remains an under-studied area in the growth literature. In the areas of industrial transformation, recent studies such as Agénor and Dinh (2013) developed a growth framework with heterogeneous labour. However, they do not account for foreign multinationals (MNCs), which along with human capital, have been documented in contributions such as Nelson and Pack (1999) and Amsden (2001) to play a significant role in the East Asian development experience. Moreover, the impact of FDI on economic growth, their interaction with domestic human capital, as well as the determination of the different composition of FDI types within a developing host economy, remain elusive in the FDI-growth literature, more so in terms of theoretical model of endogenous growth with elements of industrial transformation. While the existing empirical literature did fill some gaps, there remain a wide range of contradictory findings in terms of whether FDI does promote domestic innovation and consequently, growth ${ }^{1}$. To further complicate matters, contributions such as Markusen and Trofimenko (2009) argue that, to truly understand the knowledge conduit role of foreign MNCs in a developing host economy, a study should attempt to model FDI in a more disaggregated form [instead of its traditional stock measure] - the foreign experts themselves - since innovation expertise is embodied in human capital ${ }^{2}$. In spite of these complications, what we do know from the literature are that: (i) there seems to be some form of sequential entry dynamics for foreign

\footnotetext{
${ }^{1}$ For instance, Haddad and Harrison (1993) and Djankov and Hoekman (2000) are examples of studies that found negative or insignificant spillover and growth effects, whereas Borensztein et al. (1998) and Blomström and Sjöholm (1999) are examples of studies that find positive effects.

${ }^{2}$ Markusen and Trofimenko (2009) do attempt to model the micro-mechanism associated with foreign experts. However, their model is not based on a general equilibrium framework, therefore does not allow for the examination of the FDI-human capital nexus within the context of industrial transformation and economic growth.
} 
subsidiaries with regards to the operational mode chosen for their activities in a host economy [as in Dunning's (1997) renowned OLI [Ownership-Location-Internalisation advantages] framework]; and (ii) some non-linear, non-direct relationships between FDI and human capital within a host economy, suggesting potential room for policy complementarities between human capital policies and foreign investment liberalisation measures [Blomström and Kokko 2003; Kottaridi and Stengos 2010].

This paper attempts to fill these gaps in the literature by extending the FDIless multi-sectorial industrial transformation framework of Agénor and Dinh (2013) to address this FDI-human capital-imitation-innovation-growth nexus in the context of a developing host economy. A completely new, stylised foreign expert-based institutional framework for MNC operations is developed to determine the FDI composition in a developing host economy ${ }^{3}$. Second, in the context of Dunning's OLI framework, this can be viewed as another theoretical contribution in that we attempt to formally model 'internalisation advantage' for the first time in an endogenous growth setting, as being driven by the presence of asymmetric views by foreign experts on productivity of domestic workers. Third, as productivity is a transformation of ability, the skills acquisition decision and foreign subsidiaries' operational mode choice are linked along the same ability distribution of the host economy - a novel theoretical feature. Further, consistent with well-documented stylised facts in the FDI literature, an additional asymmetry between Vertical MNC and other MNCs is also modelled. These then allow us to study both the long-run and transitional effects of human capital and

\footnotetext{
${ }^{3}$ The framework is developed in consistent with the dualistic nature of FDI in developing countries, where foreign MNCs tend to treat host economy as merely an investment platform with little interdependence between MNCs and local markets [see Feder (1983) and Aurangzeb and Stengos (2014)]. Nevertheless, while the dualistic nature of studies in the tradition of Feder (1982) arises due to the characteristics of export platform FDI (EPFDI), the dualistic nature here arises due to foreign experts having additional quality preferences. This, the high-dimensionality of the model, and that the key issue examined is the determination of MNC-composition and how they are tied to human capital in a host economy, mean developing a model framework without explicitly considering exports will be sufficient to understand the issues at stake.
} 
FDI-promoting policies, as well as a composite of these policies.

To preview, the policy experiment results show that the implementation of foreign investment liberalisation measures in a typical developing host economy is not a matter of straightforward provision of investment incentives. Indeed, we find that an investment liberalisation measure that is balanced and targeting all types of foreign firms is more innovation- and skills acquisition-promoting than disproportionate ones biased towards selected types of foreign firms. Further, in the context of the parameterised version of the model, a threshold doing-business cost value is identified for the FDIgrowth nexus, below which standalone investment liberalisation measure is no longer enough to drive output growth. Overall, the results underline the importance of combining human capital and FDI-promoting policies to drive industrial transformation, especially if the government of a host economy intends to maximise the benefits of policy complementarities. Indeed, such a composite programme is more effective when there is a high rate of technological diffusion in the host economy.

The rest of the paper is structured as follows. Given the scarcity of literature and the inherent difficulties in the modelling of the different types of MNCs in a developing host economy, Section 2 provides a brief discussion on the rationale of the modelling approach for the MNC-composition framework, guided by the FDI literature on the various policy issues that the model attempts to address. Section 3 presents an overview of the model. Model calibrations are discussed in Section 4. In Section 5, the various policy experiments analysed are reviewed. Section 6 concludes the paper.

\section{FDI heterogeneity in developing host economy}

To guide the construction of a MNC-composition framework for such an inherently heterogeneous phenomenon, we introduce a hierarchy of internalisation decision-making 
with regards to MNC mode. Having first differentiated vertically-integrated MNCs into innovation-enhancing and non-knowledge type and lumped the latter with other nonmandatory investment commitments [to be categorised generally as Nonmandated], we can establish an order of Nonmandated-Horizontal-Vertical MNC types that matches their respective importance in the host economy's spillover. This is based on a survey of the literature on FDI and economic development, where there appears to be different roles played by different types of MNCs across different production activities of a host economy.

Empirically, global FDI flows are documented by Brainard (1997) and Markusen and Maskus (2002) to be predominantly driven by Horizontal MNCs. However, their definition of FDI composition is based on the Horstmann-Markusen-Venables (HMV) interpretation [Horstmann and Markusen 1987, 1996; Markusen and Venables 1999], which tends to ignore the different aspects of factor endowment considerations that leads to a necessary further distinction of vertically-integrated MNC activities. As documented in international production fragmentation studies such as Athukorala (2005), Athukorala and Hill (2010), the fragmented production process of vertically-integrated MNCs often generates various niches across different value chains that have vastly different resource requirements, with some being more technological- and skill-intensive than others. Moreover, the various FDI-targeting rules and ownership stipulations imposed in developing economies often inadvertently result in many nonmandated subsidiaries of MNCs, in forms such as technological licensing agreements and minority stakes in joint-ventures [Saggi 2002]. As MNCs often treat such commitments as nonmandated subsidiaries internally, these result in MNCs that are neither imitation- nor innovation-enhancing [see D'Costa (2002), for example]. We group these MNC mode as 'Nonmandated MNC'.

Consistent with Dunning, firms are said to opt for Horizontal over Vertical mode 
as the initial form of entry due to know-how advantage over rivals, and the latter tends to be more costly too [Markusen 1995; Horstmann and Markusen 1996]. However, due to factors such as agency or information cost, MNCs tend to first establish basic nonmandated subsidiaries as default entry mode [Saggi 2002], which does not seem to play much of a role in driving industrial development, save for in the poorest lowincome economies deprived of basic industrial structures. After that, both Horizontal and Vertical MNCs tend to invest in knowledge-intensive industries and therefore prefer host economies with human capital [Borensztein et al. 1998]. However, given that the costs incurred by not getting access to high quality human capital is much lower for horizontal operations, foreign firms would more likely opt for the Horizontal MNC mode. Indeed, foreign subsidiaries are only inclined to send in foreign experts with sophisticated innovation know-how if the pool of human capital of a host economy is highly productive [Gersbach and Schmutzler 2011]. This implies that the top foreign experts coming in via Vertical MNCs are likely to have an additional layer of preference to distinguish the brightest of the most skilled workers.

For a developing host economy with some stocks of human capital, a Horizontal MNC is likely to benefit the imitation activities, while a Vertical MNC would benefit innovation. Furthermore, a mixture of policies is often needed in the context of middle-income economies as they often do not have the appropriate policy combination to improve technology transfer, absorption capacity, and diffusion [Agénor 2016]. Given that there appears to be indirect, nonlinear relationships between human capital and FDI-promoting policies, the use of a mixture of these policies will have to be examined. Nonetheless, as pointed out in studies such as Blomström (2002), OECD (2008), and Olney (2013), overly narrowed investment incentives have also been documented to result in adverse signalling effects for many host countries, in that many generous incentives targeted solely at top quality MNCs have failed to achieve intended results. 
This is often known as the key finding of the 'race-to-the-bottom' literature - a phenomenon that can be explained by the increasing cost feature [faced by leading foreign innovation experts] introduced in the model, as seen later.

\section{The Model}

The domestic sector is largely similar to Agénor and Dinh (2013), though non-pecuniary externalities associated with presence of foreign experts are introduced in the knowledge sectors. Specifically, the skills acquisition feature and five production sectors are retained. For the foreign sector, to avoid further complicating a sophisticated model, the determination of the different types of foreign subsidiary mode operating in the host economy is largely independent of domestic production.

It is assumed that there is only one foreign source country that deploys subsidiary units in the form of experts to the host economy. Dunning's 'internalisation advantage' seeks to understand how foreign MNCs shape their 'in-house' preference with respect to the involvement in different production of a host economy. To construct a stylised framework that links this idea to the human capital distribution of the host economy, we adopt a nested Dixit-Stiglitz CES value function framework that is often used empirically to model heterogeneous firms along a continuous distribution [see Brambilla et al. (2009) for example]. Further, each subsidiary unit consists of one foreign expert with specific process know-how that is only available in the foreign source country. Specifically, standardisation know-how [used in imitation] for Horizontal MNC, and sophisticated know-how [used in innovation] for Vertical MNC. Consequently, the presence of Vertical MNC is a necessary condition for innovation sector to exist. As our focus is on middle-income economy with both imitation and innovation sectors, the role of nonmandated subsidiaries in domestic production is abbreviated, modelled only 
as a base entry mode.

As a result of foreign firms being effectively experts with specialised human capital, a dichotomous relationship exists between domestic and foreign firms. For domestic firms, only the average productivity of workers matters. For foreign subsidiaries, they perceiving heterogeneity among the productivity of domestic workers. As individual ability of domestic workers is not fully observable to foreign firms [though they do know the overall distribution], for two different skilled workers used to produce a same blueprint variety, foreign experts would have an additional layer of preference to be 'matched' to a worker with higher productivity - a trasformation of ability - hence resulting in a Melitz (2003) type of sorting process. In deciding on operational mode, foreign experts are therefore sorted along the ability distribution of the host economy, resulting in different threshold values for different modes of operation. Consequently, these create an indirect link between the foreign MNCs' operational choice and domestic workers' skills acquisition decision, due to the implicit 'productivity requirement'induced information cost $^{4}$. Lastly, a demand feedback channel from the industrial state of host economy to MNC composition-determination is also introduced using an endogenous preference parameter in the foreign experts' objective function, consistent with the international product market dimension described by Felipe et al. (2012).

\subsection{Domestic Sectors in Host Economy}

Households: There is a continuum of dynastic representative households growing at an exogenous rate $n>0$. Given initial number of members, $L_{0}$ in each household, the size of the representative family at time $t$ is $L_{t}=\exp (n t) L_{0}$. Each individual within a

\footnotetext{
${ }^{4}$ Uncertainty of such nature may broadly be known as some sort of information cost, arising from asymmetry in either demand or supply factors. An example of such cost is examined in Hortsmann and Markusen (1996), though our paper specifically attempts to link this choice of MNCs to the ability distribution of workers in the host economy.
} 
household is assumed to possess identical ability level, $a$, though different abilities are assumed at the household level. Ability follows a Pareto distribution, indexed by $a \in$ $\left[a_{m}, \infty\right)$, with probability density function $f(a)=\chi a_{m}^{\chi} / a^{1+\chi}$, cumulative distribution function $F(a)=1-\left(a_{m} / a\right)^{\chi}$, and mean ability of the population $\chi a_{m} /(\chi-1), \chi>2$ and $a_{m}>1$. Solving the household's intertemporal utility maximisation problem,

$$
\max U_{t}^{a}=\int_{t}^{\infty} \exp [-(\rho-n)(s-t)] L_{0}\left[\frac{1-\left(c_{t}^{a}\right)^{1 / \sigma}}{1-\frac{1}{\sigma}}\right] d s
$$

subject to budget constraint, $\dot{W}_{t}^{a}=r_{t} W_{t}^{a}+(1-\tau) Y_{t}-L_{t} c_{t}^{a}$, yields the familiar Euler equation at the aggregate level,

$$
\frac{\dot{C}_{t}}{C_{t}}=\sigma\left(r_{t}-\rho\right)+n
$$

Note that $r_{t}$ is the riskfree market interest rate, $Y_{t}$ the economy's output of final goods, $\tau \in(0,1)$ the tax rate on income, $\rho>0$ the subjective discount rate, $\sigma$ the constant elasticity of intertemporal substitution, and the utility function of individual household member [depends on individual member's consumption, $c_{t}^{a}$ ] assumes a constant relative risk aversion form. It is also assumed that agents do not value leisure, hence face no disutility from working or skills acquisition. Each representative household allocates consumption equally among its members, and is not allowed to borrow.

In terms of skills acquisition, individual members decide whether to acquire skills or work immediately as unskilled workers, taking wages and interest rate as given. Skill acquisition decisions are therefore made to maximise the discounted wage income. An individual with ability $a \in\left[a_{m}, \infty\right)$, fully observable by both domestic firms and individuals, can either choose to enter the labour force at $t$ as an unskilled worker to earn wage $w_{t}^{U}$ [independent of worker's ability], or decide to undergo training by incurring a training cost, $\Gamma$, with efficiency of training being $\xi>0$, before entering 
labour force at $t+T$ as a skilled worker and earns $a^{\xi} w_{t}^{S}$. Based on a generalised specification of Dinopoulos and Segerstrom (1999), an individual with ability $a \in$ $\left[a_{m}, \infty\right)$ would therefore opt to become a skilled worker if and only if

$$
\int_{t+T}^{\infty} \exp [-\rho(s-t)] a^{\xi} w_{s}^{S} d s-t^{\prime} c_{t} \geq \int_{t}^{\infty} \exp [-\rho(s-t)] w_{s}^{U} d s
$$

where $t c_{t}=\int_{t+T}^{\infty} \exp [-\rho(s-t)] \Gamma a^{\xi} w_{s}^{S} d s$ is the discounted value of the cost, assumed to be proportional to the skilled wages at $\Gamma \in(0,1)$.

There exists a threshold level of ability $\hat{a}_{t}$ such that (3) holds as an equality, expressed as $\hat{a}_{t}=\left[\exp (\rho T) \cdot\left(w_{t}^{U} /(1-\Gamma) w_{t}^{S}\right)\right]^{1 / \xi}$. If skills acquisition is assumed to take place instantaneously ${ }^{5}$, we can simplify it to

$$
\hat{a}_{t}=\left[w_{t}^{U} /(1-\Gamma) w_{t}^{S}\right]^{1 / \xi}
$$

Given Pareto distribution and that productivity of unskilled workers is assumed to equal unity, the share of unskilled labour supply, $\theta_{U, t}$ at time $t$ equals

$$
\theta_{U, t}=\frac{L_{U, t}}{L_{t}}=\int_{a_{m}}^{\hat{a}_{t}} f(a) d a=\left[1-\left(a_{m} / \hat{a}_{t}\right)^{\chi}\right]
$$

Given (5), the raw supply of skilled labour at time $t$ is calculated as $L_{t} \int_{\hat{a}_{t}}^{\infty} f(a) d a=$ $\left(a_{m} / \hat{a}_{t}\right)^{\chi} L_{t}$, while the share of the effective supply (having accounted for average productivity of workers) of skilled labour, $\theta_{S, t}$, is

$$
\theta_{S, t}=\frac{L_{S, t}}{L_{t}}=\int_{\hat{a}_{t}}^{\infty} a f(a) d a=\frac{\chi a_{m}^{\chi}}{\chi-1}\left(\hat{a}_{t}\right)^{1-\chi}
$$

${ }^{5}$ Given the infinite horizon nature of the model, we follow Eicher and García-Peñalosa (2001) and Agénor and Dinh (2013) in imposing the assumption of $T=0$. Knowing that individuals live forever in this model, any training period specified within $(0, T)$ is small with respect to infinity and therefore is treated as taking place instantaneously. 
Imitation: The imitation sector produces imitative blueprints that are purchased by firms producing basic intermediate inputs in the intermediate goods sector. Firms specialized in imitation employ only unskilled labour, in quantity $L_{U, I, t}$. There is no aggregate uncertainty in the research technology. The production flow, $\dot{M}_{t}^{I}$ at any time $t$ is given by expressed as:

$$
\dot{M}_{t}^{I}=\left(n_{F H, t}\right)^{\psi_{1}^{I}}\left(M_{t}^{I}+\psi_{2}^{I} n_{F V, t} M_{t}^{R}\right)\left(\frac{L_{U, I, t}}{L_{t}}\right), \quad \text { where } \psi_{1}^{I} \geq 0 \text { and } \psi_{2}^{I} \in \mathbb{R},
$$

with the specification of $L_{U, I, t} / L_{t}$ consistent with the 'dilution effect' discussed in Dinopoulos and Segerstrom (1999).

The productivity component of imitative goods depends on: (i) a standard initial stock of blueprints $\left(M_{t}^{I}\right)$, as in Jones's (2005) 'standing-on-shoulders' effect, though at constant return [Ang and Madsen, 2015] ; (ii) size of the presence of Horizontal MNCs, which given our definition of foreign firms, refers to the total number of foreign experts that bring 'know-how' to imitation production [expressed in proportion of total foreign firms, $\left.n_{F H, t}\right]$; and (iii) an externality term associated with the size of Vertical MNCs in the innovation sector. As discussed earlier and implied in studies such as Markusen and Maskus (2002), on aggregate, Horizontal FDIs are most likely to be imitation-enhancing, though an argument could be made for $\psi_{1}^{I}<0$ if multinationals preemptively price domestic competition out of markets using their ownership of superior technology, as described in Horstmann and Markusen (1987). The externality term, $\psi_{2}^{I} n_{F V, t} M_{t}^{R}$, indicates a spillover channel from the innovation sector. Consistent with the industrial transformation process, as the size of the innovation sector grows and more foreign subsidiaries opt to switch to operating as Vertical MNCs, we would expect the sign of $\psi_{2}^{I}$ to be negative. Nonetheless, given that positive empirical evidence is also reported in some studies with regards to leading foreign innovators' impacts on 
domestic firms' productivity, there is a possibility of a mildly positive $\psi_{2}^{I}$ too ${ }^{6}$. As such, the parameter, $\psi_{2}^{I}$, as well as the stepping stone parameter, $\psi_{2}^{R}$ (introduced in the innovation sector), are examined across different values using sensitivity analysis.

The optimisation problem of firms in the imitation sector is to select the amount of unskilled labour to employ so as to maximise profits of $\Pi_{t}^{I}=R_{t}^{I} \dot{M}_{t}^{I}-\left(1+\Lambda^{I}\right) w_{t}^{U} L_{U, I, t}$, subject to $(7)$, taking the imitative blueprint price $\left(R_{t}^{I}\right)$ and unskilled wage rate $\left(w_{t}^{U}\right)$ as given. The parameter $\Lambda^{I}$ is introduced as a proportionate cost factor in the imitation sector that captures the impact of labour market distortions (for instance, additional hiring and firing costs arising from non-competitive labour market practices). The interior solution for unskilled labour employment in imitation $\left(L_{U, I, t}>0\right)$ is given by:

$$
w_{t}^{U}=\frac{1}{1+\Lambda^{I}} \frac{R_{t}^{I} \Phi_{t}^{I}}{L_{t}}
$$

Innovation: Firms in the more skill-intensive innovation sector produce innovative blueprints using only skilled labour $\left(L_{S, R, t}\right)$. There is no aggregate uncertainty in innovation. The research production flow at any time $t$ is given by

$$
\dot{M}_{t}^{R}=\left(n_{F V, t}\right)_{1}^{\psi_{1}^{R}}\left(M_{t}^{R}+\psi_{2}^{R} M_{t}^{I}\right)\left(\frac{L_{S, R, t}}{L_{t}}\right), \text { where } \psi_{1}^{R} \geq 0 \text { and } \psi_{2}^{R} \geq 0
$$

As in the imitation sector, the production technology of innovative goods captures the key knowledge spillover properties. Following Agénor and Dinh (2013), the research process of innovation depends on both the stock of innovative and imitative blueprints, consistent with the stepping stone effect of imitation introduced by Glass (2010). The productivity gains associated with stepping stone effect of imitative goods may be

\footnotetext{
${ }^{6}$ Empirical studies specifically in the area of international production networks, such as Athukorala (2005) and Kam (2013), find the presence of a positive productivity spillover from leading foreign innovators to the productivity of domestic imitators, notably component part suppliers in the host economy. On the contrary, studies such as Haddad and Harrison (1993) and Djankov and Hoekman (2000) document negative effects of foreign firms on domestic firms' productivity.
} 
equal, stronger $\left(\psi_{2}^{R}>1\right)$, or weaker $\left(\psi_{2}^{R}<1\right)$ than that of innovative goods. Consistent with studies such as Markusen (1995, 1998) and Braconier et al. (2005), Vertical MNCs, $n_{F V, t}$, are specified as the relatively skill-intensive type that engage in leadingedge innovation and therefore beneficiary to domestic innovation of host economy. Similar to the imitation sector, $n_{F V, t}$ refers to the total number of foreign experts that bring sophisticated 'know-how' to innovation production in the domestic economy. Likewise, to eliminate scale effects, innovation employment is specified as a ratio to total population.

The optimisation problem of firms in the innovation sector is to select the amount of skilled labour to employ so as to maximise profits, $\Pi_{t}^{R}=Q_{t}^{R} \dot{M}_{t}^{R}-\left(1+\Lambda^{R}\right) w_{t}^{S} L_{S, R, t}$, subject to $(9)$, taking the patent price $\left(Q_{t}^{R}\right)$ and skilled wage rate $\left(w_{t}^{S}\right)$ as given. The wage in the innovation sector is affected proportionally again by a cost parameter $\Lambda^{R}$. Consistent with studies such as Haaland and Wooton (2001), $\Lambda^{R}>\Lambda^{I}$ is assumed, which means it is comparatively more expensive to hire skilled workers in innovation than unskilled workers in imitation.

For an interior solution for skilled labour employment in innovation to exist $\left(L_{S, R, t}>\right.$ $0)$, the first-order condition is given by

$$
w_{t}^{S}=\left(\frac{1}{1+\Lambda^{R}}\right)\left(\frac{Q_{t}^{R}}{L_{t}}\right)\left(n_{F V, t}\right)^{\psi_{1}^{R}}\left[1+\psi_{2}^{R}\left(\frac{m_{t}^{I}}{m_{t}^{R}}\right)\right] M_{t}^{R}
$$

Intermediate Goods: The two intermediate goods (IG) sectors are monopolistically competitive. Each producer in the basic IG sector pays a one-off royalty payment, $R_{t}^{I}$, to purchase one unit of imitative blueprint to produce one unit of basic intermediate input, while each firm in the sophisticated IG sector pay patent price, $Q_{t}^{R}$, to purchase one unit of innovative blueprint to produce one unit of sophisticated input. In both sectors, each basic IG firm maximizes profits by setting price $P_{t}^{k, s}=1 / \eta$ for good $s$, 
$\forall s=1, \ldots M_{t}^{k}$, where $k=I, R$.

In symmetric equilibrium, the associated quantity demanded for basic, $x_{t}^{I}$, and sophisticated intermediate, $x_{t}^{R}$, at individual firm level are given by

$$
x_{t}^{I}=\gamma \eta \nu\left(\frac{Y_{t}}{M_{t}^{I}}\right) \text { and } x_{t}^{R}=\gamma \eta(1-\nu)\left(\frac{Y_{t}}{M_{t}^{R}}\right) \text {, }
$$

where $\nu \in(0,1)$ is the share of basic intermediates in composite intermediates.

In terms of blueprint prices, it is derived that the maximum profit for basic IG producers in a current period $t$ is given by

$$
\Pi_{t}^{I}=(1-\eta) \gamma \nu\left(\frac{Y_{t}}{M_{t}^{I}}\right)
$$

Standard arbitrage implies that the blueprint price must equal to the present discounted stream of profits. For simplicity, we follow Agénor and Canuto (2012) and assume that all the profits of an imitative blueprint, excluding capital gain, go into the imitative blueprint price, $R_{t}^{I}$ set in equilibrium. This yields $R_{t}^{I}=\Pi_{t}^{I}$.

Meanwhile, unlike imitative blueprints, patented blueprints are infinitely-lived. Each sophisticated IG firm sets its price to maximise profits, given the perceived demand function. Their maximum profit is derived as

$$
\Pi_{t}^{R}=(1-\eta) \gamma(1-\nu)\left(\frac{Y_{t}}{M_{t}^{R}}\right)
$$

To derive the equilibrium price of a patent for sophisticated input, $Q_{t}^{R}$, standard no-arbitrage condition requires that the rate of return on private capital must equal to the rate of return on the exclusive holding of an innovative blueprint for sophisticated 
inputs, that is $r_{t}=\Pi_{t}^{R} / Q_{t}^{R}+\dot{Q}_{t}^{R} / Q_{t}^{R}$, which can be rearranged to yield

$$
\dot{Q}_{t}^{R}=r_{t} Q_{t}^{R}-\Pi_{t}^{R}
$$

Final Output: There is a continuum of identical domestic firms producing a homogenous final good, indexed by $i \in(0,1)$. Production by individual domestic firm $i$ requires the use of firm-specific private capital, $K_{t}^{i}$, skilled labour, $L_{S, Y, t}$, unskilled labour, $L_{U, Y, t}$, and composite intermediate input, $X_{t}^{i}$. Production by individual firm $i$ takes the form of a standard Cobb-Douglas specification:

$$
Y_{t}^{i}=\left(L_{S, Y, i, t}\right)^{\beta^{S}}\left(L_{U, Y, i, t}\right)^{\beta^{U}}\left(X_{t}^{i}\right)^{\gamma}\left(K_{t}^{i}\right)^{\alpha}\left[\frac{K_{t}}{\left(L_{t}\right)^{\iota}}\right]^{\varrho},
$$

where $\varrho>0, \iota>0, \alpha \in(0,1), \beta^{S} \in(0,1), \beta^{U} \in(0,1), \gamma \in(0,1)$, and $\alpha+\left(\beta^{S}+\beta^{U}\right)+\gamma=$ 1 to reflect constant returns to scale in firm-specific inputs $L_{S, Y, i, t}, L_{U, Y, i, t}, X_{t}^{i}$, and $K_{t}^{i}$. The economy-wide aggregate stock of private capital, $K_{t}=\int_{0}^{1} K_{t}^{i} d i$, asserts a conventional learning externality at magnitude $\varrho$, but is subject to a congestion effect of $\iota$ due to the total population size, $L_{t}$.

Standard profit maximisation by identical firms in a symmetric equilibrium yields first-order conditions for $r_{t}, w_{t}^{S}, w_{t}^{U}, x_{s, t}^{I}$, and $x_{s, t}^{R}$. These are

$$
\begin{gathered}
r_{t}=\alpha \frac{Y_{t}}{K_{t}}-\delta, \\
w_{t}^{S}=\frac{\beta^{S}}{1+\Lambda^{Y}} \frac{Y_{t}}{L_{S, Y, t}}, \quad w_{t}^{U}=\frac{\beta^{U}}{1+\Lambda^{Y}} \frac{Y_{t}}{L_{U, Y, t}}, \\
x_{s, t}^{k}=\left(\frac{\gamma \nu^{k} Z_{t}^{k}}{P_{t}^{k, s}}\right)^{1 /(1-\eta)}, \quad s=1, \ldots M_{t}^{\varkappa}, \quad \text { with } Z_{t}^{k}=Y_{t} / \int_{0}^{M_{t}^{k}}\left(x_{s, t}^{k}\right)^{\eta} d s,
\end{gathered}
$$

where $k=I, R, \nu^{I}=\nu, \nu^{R}=1-\nu, P_{t}^{I, s}\left(P_{t}^{R, s}\right)$ is the price of basic (sophisticated) 
intermediate good $s, w_{t}^{S}\left(w_{t}^{U}\right)$ the skilled (unskilled) wage rate, $r_{t}$ the net rental rate of private capital, $\delta \in(0,1)$ the depreciation rate of private capital, and $\Lambda^{Y}$ the sectorspecific labour hiring cost mark-up.

Given that both the technology and demand for all specific intermediate type are the same, the equilibrium for both intermediate types are symmetric too. In a symmetric equilibrium, $\int_{0}^{M_{t}^{I}}\left(x_{s, t}^{I}\right)^{\eta} d s=M_{t}^{I}\left(x_{t}^{I}\right)^{\eta}$ and $\int_{0}^{M_{t}^{R}}\left(x_{s, t}^{R}\right)^{\eta} d s=M_{t}^{R}\left(x_{t}^{R}\right)^{\eta}$. The composite intermediate inputs can then be written as

$$
X_{t}=\left[\left(M_{t}^{I}\right)^{1 / \eta} x_{t}^{I}\right]^{\nu}\left[\left(M_{t}^{R}\right)^{1 / \eta} x_{t}^{R}\right]^{1-\nu},
$$

where $x_{s, t}^{I}, s \in\left(0, M_{t}^{I}\right)$ refers to basic intermediate inputs, $x_{s, t}^{R}, s \in\left(0, M_{t}^{R}\right)$ sophisticated intermediate inputs, $\eta \in(0,1)$ and $1 /(1-\eta)>1$ the price elasticity of demand for each intermediate input. ${ }^{7}$

To derive an expression for the aggregate final output of the economy, the number of firms engaged in the production of final goods is normalised to unity, $Y_{t}=\int_{0}^{1} Y_{t}^{i} d i$, which implies that on aggregate, $L_{S, Y, t}=\int_{0}^{1} L_{S, Y, i, t} d i, L_{U, Y, t}=\int_{0}^{1} L_{U, Y, i, t} d i$. Using (15), the aggregate final output $Y_{t}$ can be written as

$$
Y_{t}=\left(L_{S, Y, t}\right)^{\beta^{S}}\left(L_{U, Y, t}\right)^{\beta^{U}}\left(X_{t}\right)^{\gamma}\left(K_{t}\right)^{\alpha}\left[\frac{K_{t}}{\left(L_{t}\right)^{\iota}}\right]^{\varrho} .
$$

Finally, the law of motion for the private capital is given by:

$$
\dot{K}_{t}=I_{t}-\delta K_{t}
$$

\footnotetext{
${ }^{7}$ The coefficient $\nu$ is fixed at a constant value for the benchmark case. However, for the endogenous technological diffusion case, it is modelled by a generalised logistic curve, where: $\nu_{t}=f\left(m_{t}\right)=$ $\nu_{m}+\frac{\left(\nu_{M}-\nu_{m}\right)}{\left[1+\exp \left\{-\zeta\left(m_{t}-m_{I}\right)\right\}\right]^{1 / v}}$, where $\nu_{m}, \nu_{M} \in(0,1)$ are the lower and upper bounds (asymptotes) of $\nu_{t}, \zeta$ the technological diffusion rate, $v>0$ the corresponding asymptote value, and $m_{I}$ the inflection point for the industrial composition ratio, $m_{t}$.
} 


\subsection{Foreign Sector}

Stylised Framework to explain 'Internalisation advantage': To characterise the mechanics of foreign subsidiaries' deployment, we use a three-staged, nested DixitStiglitz CES objective function framework adapted from Allanson and Montagna (2005) and Brambilla et al. (2009). In each period, it is assumed that there is a mass of foreign subsidiaries, $j=1, \ldots, N_{F}$, entering the host economy, with the salaries/profits of the experts/subsidiaries assumed, for simplicity, to be paid by the planner of the foreign source economy.

Specifically, in the first stage, the planner of the foreign source economy determines the allocation of aggregate salary expenditure for experts deployed overseas. Based on a standard Cobb-Douglas value maximisation specification, $\max u_{t}^{F}=z_{H, t}^{\varrho} z_{q, t}^{1-\varrho}$, in each time period, where the exogenously given aggregate salary expenditure $\left(I^{F}\right)$ is allocated between salary expenditure for experts in our host economy of interest $\left(z_{q}\right)$ and for simplicity, other host economies collectively $\left(z_{H}\right)$. This yields $y_{t}^{F}=(1-\varrho) I_{t}^{F}$, where $y^{F}$ is the total salary expenditure allocated for the specific host economy examined. By definition, $y_{t}^{F}=w^{F} N_{F, t}$ too, where $w^{F}$ is some exogenously given wage rate paid by the foreign headquarter and $N_{F, t}$ is the total number of foreign experts in the host economy studied.

Having determined the allocation in the first stage, a stylised institutional approach is specified in the second stage. Depending on the mode chosen, 'investment' in the host economy is assumed to be in terms of the intermediate variety an expert is randomly matched to. Collectively, the pool of foreign experts assigned to the host economy forms a representative value function over a composite of intermediate varieties, with a further layer of 'shadow quality' ascribed to capture the preference of foreign experts to be matched to workers of higher productivity, within the same variety type that 
they are matched to. ${ }^{8}$

Specifically, the value function is given by

$$
U_{t}^{F}=\left\{\left(\int_{j=0}^{N_{F}}\left[\int_{s=0}^{M_{t}^{I}} \gamma_{1, t}\left(x_{s, F H, t}^{I}\right)^{\frac{\sigma^{F}-1}{\sigma^{F}}} d s+\int_{s=0}^{M_{t}^{R}} \gamma_{2, t}\left(x_{s, F V, t}^{R}\right)^{\frac{\sigma^{F}-1}{\sigma^{F}}} d s\right]^{\frac{\theta^{F}-1}{\theta^{F}}} d j\right)\right\}^{\frac{\theta^{F}}{\theta^{F}-1}},
$$

where $M_{t}^{I}, M_{t}^{R}$ denote the imitative and innovative varieties over Horizontal, $x_{s, F H, t}^{I}$, and Vertical investments, $x_{s, F V, t}^{R} ; \sigma^{F}$ and $\theta^{F}$ are elasticities of substitution within and between intermediates, with $\sigma^{F}>\theta^{F}>1$ assumed as in Brambilla et al. (2009). $\gamma_{2, t}$ and $\gamma_{1, t}$ represent foreign preferences for investment of Vertical and Horizontal MNC respectively. ${ }^{9,10}$

Solving the optimisation problem with a nested foreign preference structure would yield a series of theoretical investment demand functions and shadow investment prices for each variety $s$ and productivity difference-induced quality $j$.

FDI Compositions in Host Economy: In stage three, a firm's dynamic entry decision is modelled as a static decision in opting for investment mode. ${ }^{11}$ Upon entry, foreign firms first assume a Nonmandated MNC mode and to simplify matters, no subsequent exit is allowed. Further, in each period $t$, a firm can opt to stay as Nonmandated MNC [incurring a basic 'doing-business' cost of $F_{0}$ ]; incurring additional cost, $F_{1}$ on top of $F_{0}$ to upgrade into Horizontal MNC; or incur $F_{0}+F_{2}$ to operate as a Vertical

\footnotetext{
${ }^{8}$ By construction, the 'quality difference' between investments in a host country for the foreign experts in this model reflects solely the perceived difference in productivity between the workers employed in the intermediates they are matched to.

${ }^{9}$ As shown later, foreign preferences are endogenous to the state of industrial development of a host economy, providing a key feedback channel of the host economy's industrial state to FDI via the product market dimensions. Nevertheless, it is taken as given by the pool of foreign experts when solving for the optimisation problem in every period.

${ }^{10}$ Since not all destinations of host economies have an innovation sector, we can set $x_{s, t}^{R}=0$ in the value function if we are interested in a host economy without an innovation sector. Also, since we assume non-mandated subsidiaries play no role in domestic production, we do not optimize their preferences.

${ }^{11}$ The heterogeneous foreign firms are assumed to behave in a homogenous manner within the same FDI type.
} 
MNC. $F_{2}>F_{1}>F_{0}$ is assumed. In the context of each foreign subsidiary being a foreign expert, these mean foreign subsidiaries have the option to 'upgrade' and bring in an expert with more advanced processes in every period, by incurring higher cost. ${ }^{12}$

Unlike domestic firms, each foreign expert coming in with know-how perceives heterogeneity among productivity of domestic workers. This asymmetry leads to a 'productivity requirement'-induced information cost component, $1 / \varpi$, that is implicitly priced in by foreign experts when deciding on the choice of operational mode. This productivity is a transformation of ability. For simplicity, a one-to-one relationship is assumed, where $\varpi=a / \tilde{a}$, with $a$ being value along the ability distribution of the host economy and $1<\tilde{a}<\infty$ some exogenously specified constant value. $1 / \varpi$ is therefore also characterised by a Pareto distribution. Due to persistence, for those who have become skilled, it is assumed that a more able individual pre-skills acquisition would remain more productive over another individual with lower ability pre-skills acquisition, resulting in a Melitz (2003) type of sorting of foreign subsidiaries on $1 / \varpi$. Specifically, for any intermediate variety $s$ at time $t$, solving (22), we can express an optimal shadow price of investment [from the perspective of foreign experts] as a function of productivity, $\varpi$, that is,

$$
P_{s, t}=\left(\frac{\sigma^{F}}{\sigma^{F}-1}\right)\left(\varpi_{s, t}\right),
$$

priced at $\sigma^{F} /\left(\sigma^{F}-1\right)>1$ times of $\varpi_{s, t} \cdot{ }^{13}$

This implies that, for any investment of variety $s$, the larger the "productivity requirement'-induced information cost is (lower $\varpi_{s, t}$ ), the lower is the theoretical in-

\footnotetext{
${ }^{12}$ Consistent with the nature of most common 'doing-business' costs surveyed, such as time to acquire permits and number of administrative procedures in transactions, these costs are treated as deadweight losses in this model.

${ }^{13}$ Given that the perceived quality difference among investment is driven by perceived heterogeneity among productivity of domestic workers, this price is implicit in nature and reflects the 'value' placed by foreign experts on a specific intermediate variety $s$.
} 
vestment price ascribed by the foreign experts. The basic idea is as follows. While a lower value of $\hat{a}_{t}$ from the labour supply side indicates a larger pool of skilled labour in the host economy, a lower value of $a$ from the perspective of foreign investors would imply a stricter entry threshold. As derived later, we would expect the model specification to result in the order of the threshold values for the three FDI types to be $a_{F V}<a_{F H}<a_{F P}$, since a potential Vertical MNC would have a stricter entry threshold [alternatively interpretable as needing a larger quantity/pool of skilled workers to offset the higher productivity requirement] than a potential Horizontal MNC.

Further, as both an additional novel feature and to ensure the solution space is bounded from below $\left[a \in\left[a_{m}, \infty\right)\right]$, a second source of asymmetry is introduced. Specifically, when a foreign subsidiary is confronted with the decision to upgrade and bring in experts with top know-how in innovation, the cost associated with the productivity requirement is subject to a parameter $\phi$, such that $\varpi^{\phi}>0, \varpi^{\prime}(\phi)<0$ is now priced by the foreign experts to reflect the increasing difficulties in telling apart the best (highest productivity) among the brightest of skilled workers. To explain this decreasing return feature intuitively, say for example, as a given value of $a$ gets smaller $[1 / \varpi$ gets larger] and smaller [note that if from the supply side, it means the actual quantity of skilled labour in host economy is actually larger], a negative value for parameter $\phi$ would indicate increasing difficulties in identifying and matching to the most productive skilled workers. As the pool of skilled workers gets larger, the brightest with the highest productivity would be harder to distinguish from other skilled workers.

The two dichotomous features discussed in the foreign sector characterise the stylised 'internalisation advantage' framework that determines FDI compositions in this model. Equation (23), together with theoretical investment demand functions across different varieties, allow us to express individual value function for a typical foreign expert $j$ opting for either Nonmandated $\left(\pi_{F P}\right)$, Horizontal $\left(\pi_{F H}\right)$, or Vertical $\left(\pi_{F V}\right)$ 
operational mode [see Appendix B]. Imposing zero profits conditions for foreign experts across the three types, and on aggregate, $P_{j}=P_{s}=L I$ is assumed in symmetric equilibrium $^{14}$, the three minimum threshold values for MNCs' internalisation decision in any period $t$ can be expressed as

$$
\begin{gathered}
\varpi_{F P, t}=\frac{a_{F P, t}}{\tilde{a}}=\left[\frac{F_{0}}{\left(\left(\sigma^{F}-1\right)^{\sigma^{F}-1} /\left(\sigma^{F}\right)^{\sigma^{F}-1}\left(y_{t}^{F}\right)^{-1}\right) P_{F, t}^{\theta^{F}-1}}\right]^{1 /\left(1-\sigma^{F}\right)}, \\
\varpi_{F H, t}=\frac{a_{F H, t}}{\tilde{a}}=\left[\frac{F_{1}}{\left(\left(\sigma^{F}-1\right)^{\sigma^{F}-1} /\left(\sigma^{F}\right)^{\sigma^{F}-1}\left(y_{t}^{F}\right)^{-1}\right) P_{F, t}^{\theta^{F}-1}\left[\gamma_{1, t}^{\sigma^{F}}(L I)^{\sigma^{F}-\theta^{F}}-1\right]}\right]^{1 /\left(1-\sigma^{F}\right)} \\
\varpi_{F V, t}=\frac{a_{F V, t}}{\tilde{a}}=\left[\frac{\left(F_{2}-F_{1}\right)}{\left(\left(\sigma^{F}-1\right)^{\sigma^{F}-1} /\left(\sigma^{F}\right)^{\sigma^{F}-1}\left(y_{t}^{F}\right)^{-1}\right) P_{F, t}^{\theta^{F}-1}(L I)^{\sigma^{F}-\theta^{F}}\left[\gamma_{2, t}^{\sigma_{F}^{F}}-\gamma_{1, t}^{\sigma_{F}}\right]}\right]^{1 /\left[\phi\left(1-\sigma^{F}\right)\right]}
\end{gathered}
$$

where $F_{0}, F_{1}, F_{2}$ are the 'doing-business' costs; $\sigma^{F}, \theta^{F}, y_{t}^{F}, \phi, \gamma_{1, t}, \gamma_{2, t}$ are as defined earlier; and $P_{F, t}$ is a theoretical aggregate shadow investment price index that is substituted out later.

To calculate the shares of foreign firms by FDI type, recall that the sorting of foreign firms follows that of $1 / \varpi$. We know that the cumulative distribution function of a typical Pareto distribution $z$, takes the form of $F(z)=1-\left(z_{\min } / z\right)^{\chi}$ for some minimum of $z, z_{\min }$. Let $F(1 / \varpi)=F(\tilde{a} / a)$. Further, by assuming that there is no exit option for MNCs, we can set $a_{F P}=\tilde{a} / a_{\min } \forall t$, where $\tilde{a} / a_{\min }$ denotes some minimum threshold value of entry by foreign firms (a large value along the ability distribution).

\footnotetext{
${ }^{14}$ This means the shadow price indices for the implicit 'investment price' of between- $\left(P_{s}\right)$ and within-variety $\left(P_{j}\right)$ are equalised, and assumed to be taken as given by the individual experts. As explained further in the Appendix, for ease of modelling, we proxy this by a time-invariant structural parameter, the Lerner Index, $L I$, which generalises market competitiveness - hence a reflection of the implicit value of investment - in the host economy.
} 
At any time $t$, the proportion of the three types of foreign firms are given by

$$
\begin{gathered}
n_{F P, t}=\frac{N_{F P, t}}{N_{F, t}}=\left[F\left(1 / \varpi_{F H, t}\right)-F\left(1 / \varpi_{F P, t}\right)\right]=\left[1-\left(\frac{a_{F H, t}}{a_{F P}}\right)^{\chi}\right], \\
n_{F H, t}=\frac{N_{F H, t}}{N_{F, t}}=\left[F\left(1 / \varpi_{F V, t}\right)-F\left(1 / \varpi_{F H, t}\right)\right]=\left[\left(\frac{a_{F H, t}}{a_{F P}}\right)^{\chi}-\left(\frac{a_{F V, t}}{a_{F P}}\right)^{\chi}\right], \\
n_{F V, t}=\frac{N_{F V, t}}{N_{F, t}}=\left[1-F\left(1 / \varpi_{F V, t}\right)\right]=\left(\frac{a_{F V, t}}{a_{F P}}\right)^{\chi},
\end{gathered}
$$

where $a_{F P}, a_{F H}, a_{F V}$ give the host economy-specific threshold value of entry for Nonmandated, Horizontal, and Vertical MNCs. While $n_{F H, t}$ in (28) is determined by both $a_{F H, t}$ and $a_{F V, t}$, given fixed $a_{F P},(29)$ shows that the lower the value of $a_{F V}$ [therefore the stricter the entry criteria for Vertical MNC], the smaller share of Vertical MNCs in the host economy. Also, (27) shows that the lower the value of $a_{F H}$ [therefore stricter criteria for Horizontal MNC], the larger the share of Nonmandated MNCs.

Some straightforward algebraic manipulations using (24)-(26) allow us to substitute out $y_{t}^{F}$ and $P_{F, t}$, and establish two threshold conditions of

$$
\begin{gathered}
a_{F H, t}=\left[\frac{F_{0}}{F_{1}}\left((L I)^{\sigma^{F}-\theta^{F}}\left(\gamma_{1, t}\right)^{\sigma^{F}}-1\right)\right]^{-1 /\left(1-\sigma^{F}\right)} a_{F P}, \text { and } \\
a_{F V, t}=\left[\frac{F_{2}-F_{1}}{F_{0}} \frac{1}{(L I)^{\sigma^{F}-\theta^{F}}\left[\gamma_{2, t}^{\sigma^{F}}-\gamma_{1, t}^{\sigma^{F}}\right]}\right]^{1 /\left[\phi\left(1-\sigma^{F}\right)\right]} a_{F P}^{1 / \phi} \tilde{a}^{(\phi-1) / \phi} .
\end{gathered}
$$

In addition, a feedback channel on the state of industrial development of a host economy to FDI composition is introduced. Specifically, consistent with Gander et al. (2009), we simplify by modelling the two foreign preference parameters $\gamma_{1}$ and $\gamma_{2}$ using a Weibull distribution, governed by a hazard function of

$$
\gamma_{1}=\left[1-h\left(\gamma_{2} ; \omega_{k}, \omega_{\lambda}\right)\right] \gamma_{2}=\left[1-\left(\frac{\omega_{k}}{\omega_{\lambda}}\left(\frac{\gamma_{2}}{\omega_{\lambda}}\right)^{\omega_{k}-1}\right)\right] \gamma_{2},
$$


where $h\left(\gamma_{2} ; \omega_{k}, \omega_{\lambda}\right)$ denotes the hazard rate of $\gamma_{2}{ }^{15}$, and $\omega_{k}$ and $\omega_{\lambda}$ are the shape and scale parameter respectively. As $\gamma_{1}$ is given by the expected value of $E\left(\gamma_{2}\right)$, this allows us to endogenise foreign preference in a single parameter, $Q^{F}$, a demand-side feedback channel depending on the state of industrial development of a host economy.

Finally, further substitutions of (30) and (31) into (27)-(29) would allow us to express $n_{F H, t}$ and $n_{F V, t}$ in terms of the threshold values, as in

$$
\begin{gathered}
n_{F H, t}=\left[\frac{F_{0}}{F_{1}}\left((L I)^{\sigma^{F}-\theta^{F}}\left(Q_{t}^{F}-\Theta_{1}\left(Q_{t}^{F}\right)^{\omega_{k}}\right)^{\sigma^{F}}-1\right)\right]^{-\chi /\left(1-\sigma^{F}\right)}-n_{F V, t}, \text { and } \\
n_{F V, t}=\left(a_{F P}^{1 / \phi} \tilde{a}^{(\phi-1) / \phi}\right)^{\chi}\left[\frac{F_{2}-F_{1}}{F_{0}} \frac{1}{(L I)^{\sigma^{F}-\theta^{F}}\left[\left(Q_{t}^{F}\right)^{\sigma^{F}}-\left(Q_{t}^{F}-\Theta_{1}\left(Q_{t}^{F}\right)^{\left.\omega_{k}\right)^{\sigma^{F}}}\right]\right.}\right]^{\chi /\left[\phi\left(1-\sigma^{F}\right)\right]},
\end{gathered}
$$

where $\Theta_{1}=\left(\omega_{k} / \omega_{\lambda}\right)\left(1 / \omega_{\lambda}\right)^{\omega_{k}-1}$, with $\dot{Q}^{F}=\dot{m}_{t}^{I}$ assumed in each period for tractability. ${ }^{16}$

As a result of the perceived heterogeneity of productivity among workers, and the assumed ability-productivity relationship, the determination of $n_{F H, t}$ and $n_{F V, t}$ in any period $t$ is driven by the sorting process along the same ability distribution, and depends on threshold ability values, $a_{F H, t}$ and $a_{F V, t}$. Naturally, these result in some degree of direct tradeoff between $n_{F H, t}$ and $n_{F V, t}$, as can be seen in (33), though it is also possible that an economy can gain in both $n_{F H, t}$ and $n_{F V, t}$.

\footnotetext{
${ }^{15}$ This means we assume that foreign investment preference in the mode of Horizontal MNC would reduce over time in regards to investment preference in the mode of Vertical MNC. While this assumption seems arbitrary, it provides a reasonable simplification that allows for feedback of industrial state in the host economy to FDI composition through only a single foreign preference channel.

${ }^{16}$ The use of $m_{t}^{I}$ in the feedback channel as a proxy that reflects the state of industrial development in a developing host economy is consistent with studies such as Yusuf and Nabeshima (2009). It provides a more general feature given that there are developing host economies that have only imitation production. Note that the industrial composition ratio, $m_{t}=m_{t}^{I} /\left(m_{t}^{R}+m_{t}^{I}\right)$ can be used in an alternative specification, though it comes with a lot more complications, and would make the subsequently derived expressions for $n_{F H, t}$ and $n_{F V, t}$ analytically intractable.
} 


\subsection{Government and Market-clearing Conditions}

All the public policies simulated in this paper are assumed to be financed by reallocating spending within the budget, so that the tax rate remains the same and the overall balance remains. As such, we can assume a simplified government, which maintains a balanced budget and cannot borrow. At each time $t$, the government taxes on final output at the rate $\tau$ to finance its expenditure $G_{t}$, as in

$$
G_{t}=\tau Y_{t}
$$

In terms of market-clearing conditions, for the final goods market, we have

$$
Y_{t}=L_{t} c_{t}^{a}+M_{t}^{I} x_{t}^{I}+M_{t}^{R} x_{t}^{R}+I_{t}+G_{t}
$$

For the skilled and unskilled labour markets, we have (in shares):

$$
\theta_{S, Y, t}+\theta_{S, R, t}=\theta_{S, t}, \text { and } \theta_{U, Y, t}+\theta_{U, I, t}=\theta_{U, t}
$$

For the foreign sector, in any given period $t$, the shares of foreign experts or subsidiaries in Nonmandated, Horizontal, and Vertical mode in the host economy sum up to one. With $n_{F P, t}$ derived residually, this means

$$
n_{F P, t}=1-n_{F H, t}-n_{F V, t}, n_{F P, t} \geq 0 .
$$

\subsection{Dynamic System and Steady State}

As shown in the Appendix, the solution of the system is characterised by a differential

algebraic system consisting of four first-order differential equations $\left(m_{t}^{R}, m_{t}^{I}, Q_{t}^{R}, z_{t}^{C}\right)$ 
and seven static equations $\left(\theta_{S, Y, t}, \theta_{U, Y, t}, \theta_{S, t}, \theta_{U, t}, Y_{t} / K_{t}, n_{F H, t}, n_{F V, t}\right)$. However, the complexity of the system precludes a full analytical characterisation of the solution.

The steady-state equilibrium is defined as an equilibrium path where the growth rate of the aggregate representative households' consumption $\left(n_{t}+\left(\dot{c}_{t}^{a} / c_{t}^{a}\right)\right)$, the growth rate of the private capital stock $\left(\dot{K}_{t} / K_{t}\right)$, the growth rate of imitative blueprints $\left(\dot{M}_{t}^{I} / M_{t}\right)$, and the growth rate of innovative blueprints $\left(\dot{M}_{t}^{R} / M_{t}^{R}\right)$ are all equal, whereas the imitative blueprint price $\left(R_{t}^{I}\right)$, the patent price $\left(Q_{t}^{R}\right)$, rate of return on private capital $\left(r_{t}\right)$, real prices $\left(P_{t}^{I, s}, P_{t}^{R}\right)$, and shadow aggregate price index $\left(P_{F, t}\right)$ are constant. We also know that $Y_{t} / K_{t}, \theta_{t}^{S, Y}, \theta_{t}^{U, Y}, \theta_{t}^{U}, \theta_{t}^{S}, n_{F H, t}$, and $n_{F V, t}$ are constant. These imply that: (i) final output, private capital stock, and private consumption all grow at the same constant rate in the steady state; (ii) labour supplies grow at the same rate as the population growth rate in steady state; and (iii) the number of foreign experts in imitation, $n_{F H, t}$, and innovation, $n_{F V, t}$, are constant. In steady state, these constancies indicate that the innovative blueprint-private capital ratio $\left(m_{t}^{R}\right)$, imitative blueprintprivate capital ratio $\left(m_{t}^{I}\right)$, as well as the private consumption-private capital ratio $\left(z_{t}^{C}\right)$ are constant, resulting in $\dot{m}_{t}^{R}=\dot{m}_{t}^{I}=\dot{z}_{t}^{C}=\dot{Q}_{t}^{R}=0$. Hence, the steady-state values $\tilde{m}^{I}, \tilde{m}^{R}, \tilde{z}^{C}$, and $\tilde{Q}^{R}$ can then be determined numerically.

The complexity of the model also means that saddlepath stability cannot be established analytically, though local stability in the vicinity of computationally derived steady states can be established for selected configurations of model parameters. Nonetheless, since it cannot be fully established analytically, some configurations of the model may result in the model being locally indeterminate. This necessitates the use of a computational method solving for a two-point boundary value problem in any policy experiment, such as the relaxation algorithm proposed by Trimborn et al. (2008). ${ }^{17}$

\footnotetext{
${ }^{17}$ The relaxation algorithm is a specific type of finite-difference method designed to overcome typical problems faced when solving multi-dimensional continuous time growth models. In addition to approximating the system of differential equations with finite-difference equations on a mesh of
} 
Unlike most conventional numerical methods for continuous time, the relaxation algorithm is more efficient in dealing with high dimensional systems and therefore allows us to trace out the unique transition dynamics numerically for each policy experiment implemented. Likewise, local saddlepath stability is also established numerically by calculating the eigenvalues of the Jacobian of the linearised system for each simulation case considered.

\section{Benchmark Parameterisation}

To illustrate possible impact of policies, the model is parameterised for an upper-middle income country with both innovation and imitation sectors, as well as having non-zero Vertical MNCs. Malaysia, a Southeast Asian economy that has successfully positioned itself as part of the global production value chain of foreign MNCs yet struggles to switch to an innovation-led growth strategy, is chosen as the economy studied.

On the household side, the annual discount rate, $\rho$, and the elasticity of intertemporal substitution, $\sigma$, are set at fairly conventional values of 0.04 and 0.27 [Agénor and Montiel 2008]. $L_{0}$ is normalised to unity, with the constant population growth rate, $n$, set at the five-year average of 1.73 percent as in 2008-12. The supply of skilled labour is measured in efficient units of human capital, and is therefore adjusted for average ability. For calibration purposes, given that firm-level distribution of skills and training expenditure in Malaysia are not reported in surveys [Sander and Hanusch 2012], the number of effective skilled labour in the model is defined as the number of workers with tertiary education. The parameterisation strategies for the remaining household parameters would therefore focus on producing an initial share of skilled workers, $\theta_{S}$

points in time, the algorithm also applies a typical error minimisation procedure of shooting method when calculating the time path of solutions. See Trimborn et al. (2008) for a full description of the algorithm. 
at 0.240 . This involves assuming initial skills acquisition cost, $\Gamma$, to be high at 25 percent of skilled wages, though given the recent establishment of meso-organisations for human capital development, such as Pembangunan Sumber Manusia Berhad, the efficiency of training, $\xi$ is set highly at 0.9 . For the ability distribution, both the lower bound value, $a_{m}$ and the Pareto index parameter, $\chi$, is set at a minimum value that would satisfy $\chi>2$ and $a_{m}>1$.

For imitation parameter, $\psi_{1}^{I}$, Lim (2015), in an empirical study using Productivity and Investment Climate Survey (PICS) dataset for Malaysia, obtains econometric estimates in the range of $0.20-0.35$ for a foreign ownership dummy. The upper estimate is used in our calibration to reflect reasonable strength of spillover in the imitation sector, therefore $\psi_{1}^{I}=0.35$. On the multiplicative parameter of $\psi_{2}^{I}$, we set $\psi_{2}^{I}=-0.3$ for the initial baseline to reflect a mildly negative tradeoff between the productivity of domestic imitators and the cross-term of leading foreign innovation experts and innovative blueprint $\operatorname{stock}^{18}$

In the innovation sector, based on Yusuf and Nabeshima (2009), we set $\psi_{1}^{R}=0.40$. The stepping stone effect parameter, $\psi_{2}^{R}$, is set initially to a high value of 9.5 to reflect the well-documented historically established industrial base in Malaysia (Kharas et al. 2010), though sensitivity analysis reported later will further assess the effect of a change in this parameter on the degree of industrial transformation.

In the final output sector, the elasticity of production with respect to private capital, $\alpha$, is set at a fairly standard value of 0.3 . The elasticity of output with respect to composite intermediate goods, $\gamma$, is set at 0.3 , which is double the value of 0.15 used by Agénor and Alpaslan (2014) for a low-income economy to reflect the industrial status

\footnotetext{
${ }^{18}$ As discussed earlier, the parameter $\psi_{2}^{I}$ can be interpreted as either a direct negative effect on imitators' productivity as the size of innovation grows or a positive productivity spillover from leading foreign innovators to domestic imitators, as documented econometrically by Kam (2013). Sensitivity analysis is therefore implemented to examine the steady-state implications under both cases.
} 
of Malaysia, though it remains slightly lower than the 0.36 used by Funke and Strulik (2000) and Sequeira (2011) for developed economies. By implication of the constant returns-to-scale assumption, that leaves a total of 0.4 between skilled and unskilled labour. Agénor and Dinh (2013) set $\beta^{U}$ at 0.2 for low-income economies. To adjust for Malaysia's middle-income country status while based on similar proportions to $\beta^{S}$, the parameter $\beta^{U}$ is set at 0.15 , which leaves $\beta^{S}=0.25$. The relative share of basic intermediate in the composite intermediate inputs, $X_{t}$, as measured by $\nu$, is set at 0.57 . By comparison, Agénor and Alpaslan (2014) use a high value of 0.90 for low-income economies. Lastly, following Agénor and Dinh (2013), the depreciation rate for private capital, $\delta$, is set at 0.068 .

For the three labour cost mark-up parameters, an initial state with the order of innovation, imitation, and final output sector in terms of rigidity is parameterised, in consistent with Sander and Hanusch (2012). In Zeufack and Lim (2013), the hiring cost parameter in their knowledge-intensive sector [their model does not distinguish between imitation and innovation] is set at 0.10 . We set this as the value for $\Lambda^{I}$, with $\Lambda^{Y}=0.05$ being half of it while $\Lambda^{R}=0.20$ doubles the value to reflect greater difficulties in hiring workers for the innovation sector. In the intermediate goods sectors, the substitution parameter $\eta$ for domestic production is set at 0.39 to capture a lower elasticity of substitution between intermediate inputs, in comparison to the 0.54 used by Funke and Strulik (2000) or the 0.60 used by Iacopetta (2011), but similar to the non-competitive scenario studied in Sequeira (2011). In our views, this captures the unique context of the Malaysian industry very well - a highly specialised global electrical and electronic component manufacturing hub, and part of the production network of large foreign MNCs. Lastly, the tax rate on final output, $\tau$, is set equal to 0.25 , which corresponds to the average effective tax rate of Malaysia.

Moving on to the foreign sector, in the representative objective function for foreign 
experts in the host economy, recall the assumption of $\sigma^{F}>\theta^{F}>1$, as in Brambilla et al. (2009). The between-variety elasticity, $\sigma^{F}$, is first set arbitrarily at 2 . The acrossvariety elasticity for foreign preference, $\theta^{F}$, is then set at 1.64 , which is parameterised to reflect a corresponding substitution parameter of 0.61, the value used by Agénor and Alpaslan (2014) for substitution parameter in the production side. This is deliberately parameterised to reflect the different preferences of foreign experts who come in with different know-how, though the combination of parameterised values for $\sigma^{F}$ and $\theta^{F}$ is reasonably consistent with studies using nested utility framework. The calibration for the Lerner Index, $L I$, is based on the average empirical estimates of profit margin, 0.2544, for Malaysian manufacturing firms by Zeufack and Lim (2013). A simple approximation measure for $L I$ is just $1-0.2544=0.7456$. For the basic doing-business cost of $F_{0}$, a value of 0.2733 is parameterised, based on the average cost of business start-up procedures as a percentage of real GDP per capita reported in the 2004-08 versions of World Bank Doing Business Surveys. For $F_{1}$ and $F_{2}$, given the imposed assumption of $F_{2}>F_{1}>F_{0}, F_{1}=0.33$ and $F_{2}=0.40$ are set, which imply that the cost incurred by foreign subsidiaries to come in with experts with standardisation and sophisticated know-how would be one-third and forty percent of a baseline price. As policy scenarios involving cuts in $F_{1}$ and $F_{2}$ are examined extensively in simulation exercises later, these initial parameterised values are intended to reflect an initial situation where it is expensive for foreign experts to operate in the host economy. In terms of the asymmetric cost parameter, $\phi=-1$ is conveniently set to reflect a linear function of $1 / \varpi$, with the negative value still allowing us to capture the growing difficulties in identifying the best among the highly skilled workers when the threshold entry value becomes increasingly lower and restrictive. ${ }^{19}$

\footnotetext{
${ }^{19}$ For the range of parameter values satisfying $\phi<0$, when a convex increasing function of information cost, $\phi<-1$, is used, the system runs into convergence problems quickly. Alternatively, $\phi>-1$ can be used to reflect a concave increasing function of $1 / \varpi$, though those calibrated values experimented make no significant difference to the results obtained.
} 
The total number of foreign experts entering the host economy, $N_{F, t}$ in each period is normalised to one. In terms of the parameters in the Weibull process used to model the evolution of foreign preferences, the shape parameter, $\omega_{k}$, and the scale parameter, $\omega_{\lambda}$, are set equal to 1 and 2 respectively. For the shares of the three different types, the FDI composition for Malaysia is estimated using data from the U.S. Bureau of Economic Analysis (BEA). Due to the constraints of existing FDI statistics classification (by broad industry or country, not MNCs' operations or value chain), the breakdown based on American MNCs' foreign affiliates from BEA is used, as it is the only national agency with sufficiently long time series of such definition. ${ }^{20}$ Based on the estimates, the initial proportion of Nonmandated $\left(n_{F P}\right)$, Horizontal $\left(n_{F H}\right)$, and Vertical MNCs $\left(n_{F V}\right)$ are parameterised to equal $0.3099,0.6737$, and 0.0164 respectively. To obtain these initial values for the MNC-composition in an initial steady state that is saddlepath stable, it turns out that the constant value $\tilde{a}$, and the constant term, $w_{m}$ in the international product market dimension feedback channel are set simultaneously at 9.55 and 3.6 respectively. Lastly, based on all the parameterised parameters, we estimate the initial value of $a_{F P}$ at 24.656 .

To establish that the initial steady state is consistent with $a_{F V}<a_{F H}<a_{F P}$, first, rearranging (29) would allow us to calculate the threshold entry value for Vertical FDI, $a_{F V}$, to equal 3.155. Then, given the values for $a_{F V}, a_{F P}$, the initial steadystate value for $n_{F H}$, and other parameters, the threshold value for Horizontal FDI, $a_{F H}$, is calculated by rearranging (28), yielding $a_{F H}=23.392<a_{F P}$. The theoretical condition of $a_{F V}<a_{F H}<a_{F P}$ is therefore satisfied in the initial steady state.

For the main variables of interest, the calibrations are as follows. From the data, we know $\theta_{S}=0.240$. Further, based on estimated statistics on the percentage share of

\footnotetext{
${ }^{20}$ The classification is based on Markusen (1998) and Braconier et al. (2005), and the financial and operating data of majority-owned nonbank foreign affiliates of U.S. is used to proxy for the composition of MNCs. See Appendix A for further details.
} 
$R \& D$ researchers in Malaysia, the share of effective skilled labour in innovation, $\theta_{S, R}$, is estimated at 0.045 . These imply that $\theta_{S, Y}=0.195$. Knowing the initial values for $\theta_{S}$ and $\theta_{S, Y}$, as well as other calibrated values $\left(a_{m}, \chi, \xi, \beta^{S}, \beta^{U}\right)$, we can calculate the unskilled labour share in final output production, $\theta_{U, Y}=0.0231$. Then, the share of unskilled labour, $\theta_{U}$, is just 0.9856. By implication, the proportion of unskilled labour working in the imitation sector is then 0.9625. On the industrial composition ratio, the average of Malaysia's share of high technological exports as percentage of total manufactured exports is calculated for the year between 2008 and 2011, yielding 0.4164. The industrial composition ratio measures the ratio, $m_{t}=m_{t}^{I} /\left(m_{t}^{R}+m_{t}^{I}\right)$, which means its initial steady-state value would equal $1-0.4164=0.5836$. In terms of measuring the degree of innovation expertise in host economy, the foreign-to-domestic innovation expertise ratio, $\Psi_{t}$, is defined as the ratio of the number of foreign experts with sophisticated know-how to the number of skilled workers in innovation sector. Recalling that both $N_{F, t}$ and $L_{t}$ are normalised to one in the model, we can therefore write $\Psi_{t}=n_{F V, t} / \theta_{S, R, t}$ to compute for the innovation expertise ratio in each period. The initial steady-state value is $\Psi_{t}=0.3672$.

For the generalised logistic curve used to examine endogenous technological diffusion later, the calibrations of $\nu_{m}=0.1, \nu_{M}=0.9$, and $m_{I}=0.55$ are applied, all of which are reasonable values for a typical S-curve. The parameter $\zeta$ is set at 1.0 to 5.0, which indicates a sensitivity analysis of diffusion rates ranging from 100 to 500 percent, and the parameter $v$ is calibrated to maintain initial steady-state values at $\nu_{t}=0.57$, $m_{t}=0.5836$, and $\Psi_{t}=0.3672$ for the different cases of $\zeta$.

Finally, for the initial steady-state growth rate of final output, a multiplicative constant is introduced to yield both an initial annual growth rate for final output and private capital stock to equal 4.3 percent per annum, which corresponds to the average growth rate for Malaysia in the period of 2008-13. Table 1 and 2 summarise 
the parameter values for the domestic and foreign sector respectively. Table 3 presents the parameters used for the generalised logistic curve.

\section{Table 1 Calibrated Parameter Values: Benchmark (Host Economy) Table 2 Calibrated Parameter Values: Benchmark (Host Economy) Table 3 Calibrated Parameter Values: Benchmark (Foreign Sector)}

\section{$5 \quad$ Policy Experiments}

In the debate on FDI-promoting policies, a key issue for developing country policymakers is often whether to adopt a broad-based foreign investment liberalisation measure or to zero in on selected leading foreign MNCs using targeted investment incentives [similar to selecting domestic 'champions' in industrial policy]. Moreover, there is also a large 'race-to-the-bottom' literature showing that many developing economies competing for FDI [often those using the latter approach] end up failing to achieve their intended results. In the context of the FDI-promoting policies in this model, we first set out to answer this question. Second, for the policies considered, we examine whether the observed results are affected by a threshold, or merely by the standard level effects. Third, we assess the question, "Does it matter whether the spillover from leading foreign Vertical MNCs to the domestic imitators [a still-contradicting empirical finding] is positive or negative?"

After that, we proceed to study the policy externalities between FDI-promoting and human capital policies. Questions to be answered include "Are these policies complementary or counteracting?" Moreover, in an environment where production structure changes as industry transforms over time, "Does endogenous technological diffusion propagate or diminish these externalities?"

For the issues of interest, policy experiments for both individual and composite pro- 
grammes are examined. As we are mostly interested in the long run effects of policy interventions, all policy experiments implemented are permanent in nature. We consider five individual policies: 3 direct measures pertinent to the costs faced by foreign subsidiaries, and 2 in the broad area of human capital policies [a supply-side measure of skills acquisition cost cut and a demand-side measure of a labour hiring cost markup cut for innovation]. Similar to Agénor and Dinh (2013), the progress of industrial transformation [measured by the industrial composition ratio $m_{t}=m_{t}^{I} /\left(m_{t}^{R}+m_{t}^{I}\right)$ ] is the key policy indicator to be examined. To measure progress on the deepening of domestic innovation expertise, the foreign-to-domestic innovation expertise ratio, $\Psi_{t}$, is introduced as it provides a more meaningful policy interpretation than the individual measures of the share of Vertical MNCs, $n_{F V, t}$, and share of skilled labour in innovation, $\theta_{S, R, t}$. In addition, to ensure that households do not permanently lose out due to transformation, the long run steady-state effect on aggregate private consumption growth $\left(\dot{C}_{t} / C_{t}\right)$ is also evaluated, with a policy option considered to be acceptable only if the growth rate is sustained or increases in the steady state. ${ }^{21}$

\subsection{Individual Policies}

The individual policies considered include: (i) a reduction in skills acquisition cost, $\Gamma$, from 0.25 to 0.18 ; (ii) a cut in the cost mark-up associated with the hiring of skilled researchers, $\Lambda^{R}$, from 0.2 to 0.0 ; (iii) an economy-wide liberalisation attempt aimed at reducing general administrative cost for all foreigners in the host economy [cutting $F_{0}$ from 0.2733 to 0.2433 ]; (iv) a targeted liberalisation measure to incentivise Horizontal

\footnotetext{
${ }^{21}$ When solving for the continuous time dynamic problems over the entire infinite time horizon, the numerical method of relaxation algorithm allocates mesh points unevenly such that the time difference between result observations generated increasingly widens over time. The steady-state result therefore would dominate other observations along the time path in any integrable measure like the conventional welfare calculations. Higher steady-state growth in aggregate private consumption therefore necessarily reflects improvement in welfare.
} 
operations [cutting $F_{1}$ from 0.33 to 0.30]; and (v) a targeted measure for Vertical MNCs [cutting $F_{2}$ from 0.40 to 0.37 ]. ${ }^{22}$ The benchmark results - both steady-state and transitional dynamics - of these policies, as well as those from selected sensitivity tests, are presented in Table 4 and Figure 1 respectively.

Briefly, we see that both the human capital policies induce more workers to invest in skills, therefore leading to an expansion in both the proportion of skilled labour employed in the final output and the innovation sectors. For both policies, the dynamics of industrial composition ratio and foreign-domestic innovation expertise ratio exhibit a 'scale-back', hump-shaped pattern [which is due to an associated gross complementarity in the form of an increase in marginal product of unskilled workers and consequently, unskilled wages, hence mitigating the skills acquisition incentive]. However, in both cases, the economy does experience a steady-state decrease in industrial composition ratio and a relative deepening in domestic innovation expertise, with the effects of the demand-side policy being more pronounced due to the stronger reallocation effect. Lastly, it is also seen that a larger stepping stone effect, $\psi_{2}^{R}=15.5$, unambiguously brings about more significant results.

\section{Table 4 Individual Policies: Steady-state Effects ; Figure 1 Individual Policies: Dynamics}

Next, we consider results with regards to the reduction in the 'doing-business' costs for foreign experts, namely the basic doing-business cost, $F_{0}$, incurred on all foreign experts in the host economy; the additional cost incurred by foreign subsidiaries of Horizontal nature, $F_{1}$; and the additional cost incurred by Vertical operation with

\footnotetext{
${ }^{22}$ The first policy may be thought of as a subsidy scheme designed to reduce the cost of pursuing advanced education or workplace training, while the other four policies concern deregulation measures to improve investment climate. These policies can be thought of as being achieved by reallocating unproductive spending within the budget, so that the tax rate remains the same and the overall balance remains.
} 
leading foreign innovation experts, $F_{2}$. Predictably, a cut in the basic cost of $F_{0}$ would unambiguously bring about positive effects on both $n_{F H}$ and $n_{F V}$. Nonetheless, for the add-on cost of $F_{1}$ and $F_{2}$, by implication of the foreign sector specification where the two assymmetries are introduced, the policy experiments produce seemingly counterintuitive results that may partly help to explain the 'race-to-the-bottom' phenomenon, where competing host economies offering the best financial incentives often do not end up attracting the best foreign innovation experts with frontier know-how. ${ }^{23}$

Balanced versus Targeted Investment Incentives: The first FDI policy issues to address is whether a developing host economy ought to pursue a balanced investment liberalisation agenda or a narrowed targeted incentive focusing only on attracting leading foreign innovation experts. Based on the simulation results, it is the former that is more innovation-enhancing for a developigng economy undergoing industrial transformation. This can be understood by first considering the standalone reduction of $F_{2}$ from 0.40 to 0.37 , which is a three percentage point-reduction in terms of the baseline theoretical price [equivalently, in relative terms, a 7.5 percent drop from the initial 0.40].

While a host economy may intend to attract more foreign experts with sophisticated know-how by reducing the additional cost incurred on them, this results in an adverse signalling effect where the proportion of foreign subsidiaries in Vertical mode is reduced. A reduction in $F_{2}$ would ceteris paribus, be expected to result in an expansion of the perceived investment value for a typical foreign experts $j$ with sophisticated knowhow. Nevertheless, given the equi-profit condition used to derive threshold value for

\footnotetext{
${ }^{23}$ These are summarised in studies on FDI policy competition, such as Blomström (2002). In essense, this branch of the literature argues that the quality of the enabling environment of investment [for examples, human capital quality], especially for foreign firms with investments in technological leadership areas, affects a country's ability to attract quality FDI more than direct investment incentives. Indeed, it can be costly and counterproductive to offer investment incentives if the 'fundamentals' of the potential host economy are bad.
} 
Vertical MNCs, $a_{F V}$, the asymmetric productivity term, $\varpi_{F V}^{\phi}$, would have to adjust, as seen from (26). The reduction in $F_{2}$ puts a downward pressure on $\varpi_{F V}$ [and increases the information cost associated with perceived productivity difference, $\left.1 / \varpi_{F V}\right]$, and this results in a lower and stricter threshold value for Vertical MNCs, $a_{F V}$. Foreign subsidiaries are therefore less willing to operate with experts in sophisticated know-how in the host economy, resulting in a reduction of $n_{F V}$.

Intuitively, these effects may be interpreted as follows. While typical direct investment incentives may be attractive to new firms, consistent with observations documented by Blomström (2002), the reduction in $F_{2}$, without an accompanying cut in $F_{0}$, can lead to an adverse signalling type of outcome. Given the asymmetric structure specified for the internalisation decision of a typical foreign innovation expert in Vertical MNC mode, foreign subsidiaries in the host economy would face increasing difficulties in discriminating the best among the most productive ones. This productivity uncertainty associated with the asymmetric cost structure of a typical Vertical MNC means a smaller $F_{2}$ in (26) would result in existing foreign subsidiaries of the host economy being relatively more wary of the information cost associated with perceived productivity difference for a typical Vertical operation, $1 / \varpi_{F V}\left[\right.$ compares to $\left.1 / \varpi_{F H}\right]$, therefore preferring the alternative of Horizontal operation and instead bringing in experts with standardisation know-how. Hence, $n_{F H}$ increases by 4.4 percentage points while $n_{F V}$ drops by 0.5 percentage points.

The expansion in $n_{F H}$ then creates a secondary effect: it leads to an expansion in imitative goods relative to innovative goods in the host economy due to a rise in productivity of imitation. This results in industrial composition ratio, $m$, rising by 5.6 percentage points, despite a relative deepening of domestic innovation expertise by 30.2 percent [ $\Psi$ declining from 0.3672 to 0.2563$]$. This relative deepening is driven by the significant drop of foreign experts with sophisticated know-how and not an increase 
in share of skilled researchers, $\theta_{S, R}$, hence not an ideal policy outcome. Lastly, the steady-state growth effect is small and mildly positive, but this is again not driven by gains in industrial transformation. Indeed, in the other sensitivity results concerning this specific shock summarised in Table 4, the adverse signalling steady-state effects associated with $F_{2}$ cut are consistently observed, with the effects on $m$ being stronger the higher $\psi_{1}^{R}$ [greater reliance of domestic innovation in Vertical MNCs], or the higher $\psi_{2}^{R}$ [greater learning associated with the stepping stone effect] is. Indeed, the simulation results are consistent with the Malaysian experience over the past two decades, where the Malaysian administration had been among the most active 'open-door' regime with respect to offering all forms of targeted incentives to attract foreign firms at the global frontier, yet failed to attract many of such foreign firms (Yusuf and Nabeshima 2009).

Next, instead of targeted incentive, consider a balanced investment liberalisation attempt aimed at reducing general administrative cost for all foreigners in the host economy. This is equivalent to a three percentage point-reduction in $F_{0}$ from 0.2733 to 0.2433. As $F_{0}$ is the basic cost incurred on all foreign MNCs, ceteris paribus, this would create incentives for foreign firms to adopt an improved mode of operation and bring in foreign experts with more advanced know-how. Given that $n_{F P}$ is treated as a residual, this would result in an unambiguous increase for both $n_{F H}$ and $n_{F V}$. For Vertical MNCs, the reduction in total cost required to be paid every period $\left(F_{0}+F_{2}\right)$ means there will be an unambiguous increase of $n_{F V}$ by 0.2 percentage points. Similarly, for Horizontal MNCs, the reduction in total cost required to be paid every period $\left(F_{0}+F_{1}\right)$ results in an increase of $n_{F H}$ by 3.8 percentage points.

The increase in both $n_{F H}$ and $n_{F V}$ leads to an expansion in both the imitation and the innovation sector, though the latter grows more in relative terms. Specifically, the industrial composition ratio, $m$, declines by 1.34 percentage points in the steady state. As the innovation sector expands relatively faster than the imitation sector, more skilled 
workers are relocated out of final output production compared to unskilled workers' reallocation to imitation. This tends to put a downward pressure on the relative wage ratio, $w^{U} / w^{S}$ [recall that it is determined by a function of $\left.\theta_{S, Y} / \theta_{U, Y}\right]$. This then creates greater skills acquisition incentives and leads to an increase in the effective supply of skilled labour. Specifically, in the steady state, these effects translate to moderate expansions in $\theta_{S}$ and $\theta_{S, R}$. The relatively small increase in $\theta_{S, R}$ comparing to $n_{F V}$ also means that the foreign-to-domestic innovation expertise ratio, $\Psi$, increases from 0.3672 to 0.4111 . In relative terms, this means domestic innovation expertise deteriorates by 12 percent, indicating a growing reliance on foreign innovation experts in the host economy.

In summary, between the two FDI-promoting policies, it is clear that the balanced and all-targeting liberalisation measure is more supportive of an economy's industrial transformation and skills expansion than the disproportionate one biased towards only the leading foreign firms, though the standalone $F_{0}$ cut does result in growing reliance on foreign innovation expertise and mildly negative growth ${ }^{24}$.

Further Analysis on FDI-promoting Policies: Given that $F_{0}$ is calibrated based on the basic doing-business cost and therefore captures the institutional quality aspect faced by foreign investors, a natural extension is to examine whether the policy results observed are influenced by the initial parameterised value, and whether there exists any threshold value. To do these, within the $F_{0} \in[0.159,0.519]$ range where the model still solves, we simulate all three FDI-promoting policies repeatedly across a grid of four decimal places. A selection of these results are presented in Table 5 .

\footnotetext{
${ }^{24}$ Ideally, the robustness of the results for $F_{2}$ shock can be improved further if we could consider a non-decreasing return specification [non-increasing costly nature to identify the best among the brightest of skilled workers] for the Vertical MNCs. However, the functional specification is also a technical necessity to ensure the solution space for $a$ is bounded. Indeed, as pointed out earlier, in any sensitivity analysis where a convex increasing function of information cost, $\phi<-1$, is used, the system runs into convergence problems quickly.
} 
For the basic doing-business cost, $F_{0}$, the same 11 percent cut is simulated for the different initial values. It is noted that there are clear level effects where the higher the initial cost of doing-business is, the larger the deviation is observed for the industrial composition ratio, $m_{t}$. This is the same for the policy of $F_{2}$ cut, but not the case of a $F_{1}$ cut and the results associated with the relative innovation expertise ratio, $\Psi$. In terms of final output growth, we identify two threshold values - one each associated with $F_{2}$ and $F_{0}$ cut.

For the targeted measure to reduce additional cost incurred by Vertical operation, $F_{2}$, we identify an initial threshold value of $F_{0}=0.4310$, above which output growth effect is negative and the model runs into convergence problem. Below this threshold, the lower the initial doing-business cost is in a host economy, the more room the aforementioned economy has, to continue relying on imitation-driven growth via ' reverse transformation'. The other more interesting threshold concerns the balanced foreign investment liberalisation measure, $F_{0}$, and is key in understanding the FDI-growth nexus in the context of this model. As noted previously with the benchmark case $\left[F_{0}=0.2733\right]$, a standalone $F_{0}$ cut results in a very mild negative growth effect. It turns out that there is a threshold value for the initial doing-business cost, below which final output growth effect is negative. This value is $F_{0}=0.2964$. The key policy implication from this analysis is therefore that, the usefulness of broad-based investment liberalisation measure in promoting output growth in a developing host economy depends on its initial doing-business cost as measured by the World Bank. For Malaysia, its initial doing-business cost is below the threshold value for her to rely solely on $F_{0}$ cut to promote output growth. However, for the other policy outcomes, we observe only the standard level effects and not any threshold effect.

\section{Table 5 FDI-promoting Policies: Steady-state Effects}


Does it matter whether the spillover from Vertical MNCs to the domestic imitators is positive or negative?: Indeed, further examination reveals a more significant parameter that affects the policy dynamics of the FDI-promoting policies considered. As seen earlier in the Imitation section, the parameter $\psi_{2}^{I}$ measures a spillover channel from Vertical MNCs' presence to the productivity of the domestic imitators. Given the contradictory empirical evidence, this value can be either positive or negative. For our policy experiments, it turns out that the choice of $\psi_{2}^{I}$ affects significantly the transition path of key policy variables. This is clear in Figure 2-4, which illustrate the transitional dynamics of the two key policy variables of interest (for different initial values of $F_{0}$ ) in the two separate regime of $\psi_{2}^{I}$ for $F_{0}, F_{1}$, and $F_{2}$ cut respectively. When $\psi_{2}^{I}>0$, for all three policies, the transition paths display cyclical properties and for some variables, overshooting patterns. In contrast, when $\psi_{2}^{I}<0$, the transition paths are a lot smoother. Nevertheless, in terms of the steadystate effects, for $\psi_{2}^{I}>0$ the magnitude of the absolute deviations from baseline tend to be larger. Hence, for policy implications, the sign does matter for the spillover channel from Vertical MNCs' activities to the domestic imitators' productivity. If a less volatile transition path for the industrial transformation process is desired, an environment where the growth of Vertical MNCs in the innovation sector would phase out the domestic imitators will be more supportive. If the steady-state magnitude of deregulation measures matters more, then an environment where domestic imitators gain from the presence of Vertical MNCs is preferred.

Figure 2 Permanent Cut of $\mathbf{F}_{0}$

Figure 3 Permanent Cut of $\mathbf{F}_{1}$

Figure 4 Permanent Cut of $\mathrm{F}_{2}$ 


\subsection{Composite Programmes}

A key goal that policymakers in developing economies often seek to achieve when implementing composite programmes involves identifying the best policy combination to reap the benefits of policy complementarities. The main premise of this study is that a composite programme delivering the best outcome of industrial transformation, overall skills expansion, and a deepening of domestic innovation expertise, while simultaneously attaining positive changes in final output and aggregate private consumption growth rates, will be the preferred composite programme. The key complementarity between labour and foreign investment liberalisation policies is therefore best illustrated here.

Consider three different composite programmes that constitute some combination of the five individual policies considered. Specifically, Composite Programme A combines both the $\Gamma$ and $\Lambda^{R}$ shocks with a balanced combination of foreign cost cuts [simultaneous reduction in $F_{0}, F_{1}$, and $F_{2}$ by 0.03]. Composite Programme $B$ combines the two with a proportionate cost cutting programme tilted towards providing investment incentives for foreign experts with know-how of technological leadership $\left[F_{0}\right.$ reduced by $0.01, F_{1}$ reduced by 0.03 , and $F_{2}$ reduced by 0.05$]$, while Composite Programme $C$ combines the $\Gamma$ and $\Lambda^{R}$ reductions with a third proportionate cost cutting programme tilted towards providing basic investment incentives to all foreigners $\left[F_{0}\right.$ reduced by $0.05, F_{1}$ reduced by 0.03 , and $F_{2}$ reduced by 0.01$]$.

The results of the three composite programmes experimented are illustrated in Table 6 and Figure 5. The transition paths of the key policy variables examined conform to what would have been expected when the effects of the individual policies are combined. Both the simultaneous foreign cost cutting programme and the proportionate cost cutting programme with $F_{0}$ cut by 0.05 produce positive deviation in the share of Vertical MNC, $n_{F V}$, in the steady state. At the same time, the skills acquisition- 
stimulating cost reduction measures of $\Gamma$ and $\Lambda^{R}$ cuts would create greater incentives for labour to not only undergo training, but also work in the innovation sector. The increase in skilled labour supply would initially put a downward pressure on skilled wages. However, due to the overall increase in skilled employment occurring in both the innovation $\left(\theta_{S, R}\right)$ and final output sector $\left(\theta_{S, Y}\right)$, a secondary effect would also be at play: the expansion of innovative blueprints relative to imitative blueprints, and conversely, the varieties of sophisticated intermediate inputs relative to basic inputs. This shift towards innovation raises the productivity of labour in that sector, which magnifies the initial effect. Nonetheless, the increase in the supply of skilled labour in final output production would also raise marginal product of unskilled workers, which then raises unskilled wages. This then mitigates the initial effect on incentives to acquire skills, and the labour market adjustment dynamics are reflected in the hump-shaped pattern associated with $m_{t}$ and $\Psi_{t}$ in Figure 5 .

The decline in imitative varieties would further feed back into the foreign firms' internalisation process, which creates a tertiary dynamic that is then reflected in the cyclical pattern of $m$ and $\Psi$. The decline in imitative varieties makes the host economy less attractive as a host to Horizontal MNCs, but at the same time improves the incentive for foreign innovation experts with sophisticated know-how to enter. In the case of Composite Programme A, this therefore mitigates the initial decline in $n_{F V}$ and results in an overall increase of $n_{F V}$ in steady state, while in the case of Composite Programme $C$, it further leads to growth in the share of foreign innovation experts in the host economy. Overall, while the host economy would experience improvements in both industrial composition and relative domestic innovation expertise under both Composite Programme $A$ and Composite Programme $C$, the balanced Composite Programme $A$ would be the better programme as it sustains aggregate private consumption growth. 
In contrast, the Composite Programme $B$ results in largely opposite results. The share of foreign experts in the Vertical MNC mode, $n_{F V}$, would decline due to the adverse signalling effects associated with the large $F_{2}$ cut. This then results in 'reverse transformation' towards imitation, less incentive to acquire skills and work in innovation sector, hence a drop in both effective skilled workers, $\theta_{S}$, and those employed in the innovation sector, $\theta_{S, R}$. In terms of steady-state aggregate private consumption growth, Composite Programme B predictably delivers the largest gain of 0.22 percentage points, but unlike the preferred Composite Programme A, this is maintained by not making progress in industrial transformation.

\section{Table 6 Composite Programmes: Steady-state Effects Figure 5 Composite Programmes: Dynamics}

Overall, the policy experiment results are consistent with the consensus views documented in Saggi (2002) and Faeth (2009), where evidence on the direct role of FDI in promoting domestic innovation is mixed, but their indirect impacts tend to be positive if their presence leads to a deepening of domestic innovation expertise. Likewise, when

the externality parameter associated with learning effects in the innovation sector [the stepping stone effect from the stock of imitative goods, $\left.\psi_{2}^{R}\right]$ is calibrated at a higher value, the steady-state effects on both the industrial composition ratio and foreigndomestic innovation expertise ratio are unambiguously more effective in all three composite programmes. This is illustrated in Figure 6, which presents the steady-state deviations of $m_{t}$ for the balanced Composite Programme $A$ across different combinations of $\psi_{2}^{R}$ and $\psi_{2}^{I}$. The strong effects associated with a larger stepping stone are consistent with Agénor and Dinh (2013).

\section{Figure 6 Composite Programme A - Industrial composition ratio}




\subsection{Endogenous Technological Change, Policy Complemen- tarities}

Lastly, the three composite programmes are examined again, in scenarios where the production parameter, $\nu_{t}$, is allowed to vary as the industrial composition ratio changes over time. The steady-state effects for the key variables of interest are presented in

Table 7 . For all three composite programmes, endogenising $\nu_{t}$ generates more sensitive results, and the higher the diffusion rate, $\zeta$ considered, the greater the steady-state effects documented. In addition, we also examine for policy complementarities between the human capital and FDI-promoting policies. As shown in Table 8, there are clearly positive policy complementarity effects, since the composite programme generates longrun gains that exceed those generated by the sum of the individual policies.

Indeed, the policy complementarity effect is stronger the higher the diffusion rate is. For instance, at the highest $\zeta$ value examined $(\zeta=5.0)$, Composite Programme $A$ would lead $\nu_{t}$ to decline from 0.57 to 0.496 . This would result in a reduction of -7.8 percentage points in the industrial composition ratio (in comparison, in the benchmark model with fixed $\nu, m$ declines by 4.9 percentage points), and expansion of $\theta_{S}$ and $\theta_{S, R}$ by 2.0 and 1.8 percentage points respectively. In terms of the deepening of domestic innovation expertise, the foreign-domestic innovation expertise ratio, $\Psi$ decreases more significantly despite both $\theta_{S, R}$ and $n_{F V}$ having increased. At the same time, the steady-state effect on aggregate private consumption growth would be higher too, growing by 0.21 percentage points. The final output growth rate increases from 4.3 to 4.5 percentage points. These indicate 'across-the-board' gains, underlying the significance of endogenous technological change in magnifying the benefits of policy complementarity between the human capital and FDI-promoting policies.

Table 7 Sensitivity Analysis: Endogenous technological change 


\section{Table 8 Policy Complementarities - Composite Programme A}

\section{Concluding Remarks}

This paper develops an imitation-innovation model with heterogeneous labour and foreign MNCs explained at the disaggregated level of foreign experts. The novel contributions include formalising a framework to explain 'internalisation advantage' [Dunning's OLI /Eclectic Paradigm] for heterogeneous MNCs and the determination of their composition. Based on Agénor and Dinh (2013), industrial transformation was measured by changes in an index of industrial structure. This idea that is Romerian-based is further supplemented by a novel foreign multinationals' sorting framework that allows us to model the dichotomous relationship between domestic and foreign firms. Unlike the former, foreign experts perceive heterogeneity among the productivity of domestic workers. As productivity is a transformation of ability, this allows us to link the skills acquisition decision and foreign subsidiaries' operational mode choice along the same ability distribution in the host economy. In addition, asymmetry is introduced specifically for Vertical MNCs to capture the increasingly costly nature for foreign experts to identify the best among the most productive workers.

Using a parameterised version of the model, we conduct both individual and composite policy experiments to examine the steady-state and transitional effects of these policies. The key policy implications derived have been discussed in the Introduction section and therefore need not be repeated here. Instead, there remain limitations in the study that future research can address. For this reasonably complicated highdimensional model, some policy elements are not pursued, largely as a self-contained measure to ease computational burden, but are obvious aspects for extensions. For instance, the role of fiscal policy in the model is minimal. Second, while the model 
establishes indirect feedback from the skills channel to FDI composition, a direct feedback channel of human capital to FDI is not modelled. For future research, notably in a model with Lucas type of disembodied human capital and more traditional modelling of FDI as capital, this would obviously be worth examining. 


\section{References}

Agénor, Pierre-Richard and Baris Alpaslan (2014) Infrastructure and industrial development with endogenous skill acquisition. Centre for Growth and Business Cycle Research Discussion Paper No. 195, University of Manchester.

Agénor, Pierre-Richard and Otaviano Canuto (2012) Middle-income growth traps. Policy Research Working Paper No. 6210, World Bank.

Agénor, Pierre-Richard and Hinh T. Dinh (2013) Public policy and industrial transformation in the process of development. Policy Research Working Paper No. 6405, World Bank.

Agénor, Pierre-Richard and Peter Montiel (2008) Development Macroeconomics. New Jersey: Princeton University Press.

Allanson, Paul and Catia Montagna (2005) Multiproduct firms and market struc-

ture: An explorative application to the product life cycle. International Journal of Industrial Organization, 23, 587-97.

Amsden, Alice (2001) The Rise of "The Rest": Challenges to the West from LateIndustrializing Economies. Oxford: Oxford University Press.

Ang, James B. and Jakob B. Madsen (2015) What Drives Ideas Production across the World. Macroeconomic Dynamics, 19, 79-115.

Athukorala, Prema-chandra (2005) Product Fragmentation and Trade Patterns in East Asia. Asian Economic Papers, 4, 1-27.

Athukorala, Prema-chandra and Hal Hill (2010) Asian Trade: Long-term Patterns and Key Policy Issues. Asian-Pacific Economic Literature, 24, 52-82.

Aurangzeb, Zeb and Thanasis Stengos (2014) The Role of Foreign Direct Investment in a Dualistic Growth Framework: A Smooth Coefficient Semi-Parametric Approach. Borsa Istanbul Review, 14-3, 133-44.

Blomström, Magnus (2002) The Economics of International Investment Incentives. 
In H. Christiansen (ed.), International Investment Perspectives, 165-83. Paris: OECD Publications.

Blomström, Magnus and Ari Kokko (2003) Human Capital and Inward FDI. Working Paper No. 167, European Institute of Japanese Studies.

Borensztein, E., Jose De Gregorio, and Lee Jong-Wha (1998) How does Foreign Direct Investment affect Economic Growth? Journal of International Economics, 45, $115-35$.

Braconier, Henrik, Pehr-Johan Norbäck, and Dieter Urban (2005) Multinational Enterprises and Wage Costs: Vertical FDI revisited. Journal of International Economics, 67, 446-70.

Brainard, S Lael (1997) An Empirical Assessment of the Proximity-Concentration Trade-off between Multinational Sales and Trade. American Economic Review, 87, $520-44$.

Brambilla, Irene, Galina Hale, and Cheryl Long (2009) Foreign Direct Investment and the Incentives to Innovate and Imitate. Scandinavian Journal of Economics, 111, 835-61.

D’Costa, Anthony (2002) Software Outsourcing and Development Policy Implications: An Indian Perspective. International Journal of Technology Management, 24, $705-23$.

Djankov, Simeon and Bernard Hoekman (2000) Foreign Investment and Productivity Growth in Czech Enterprises. World Bank Economic Review, 14, 49-64.

Dinopoulos, Elias and Paul S. Segerstrom (1999) A Schumpeterian model of protection and relative wages. American Economic Review, 89, 450-72.

Dunning, John H (1977) Trade, Location of Economic Activity and the Multinational Enterprise: A Search for an Eclectic Approach. In B. Ohlin, et al. (ed.) The International Allocation of Economic Activity, 395-418. London: Holmes and Meier. 
Eicher, Theo and Cecilia García-Peñalosa (2001) Inequality and Growth: The Dual Role of Human Capital in Development. Journal of Development Economics, 66, 17397.

Faeth, Isabel (2009) Determinants of Foreign Direct Investment - A Tale of Nine Theoretical Models. Journal of Economic Surveys, 23, 165-96.

Feder, Gershon (1983) On Exports and Economic Growth. Journal of Development Economics, 12, 59-73.

Felipe, Jesus, Arnelyn Abdon, and Utsav Kumar (2012) Tracking the MiddleIncome Trap: What Is It, Who Is in It, and Why? Working Paper 715, Levy Economics Institute.

Funke, Michael and Holger Strulik (2000) On Endogenous Growth with Physical Capital, Human Capital, and Product Variety. European Economic Review, 44, 491515.

Gander, James, Steve Reynolds and Richard Fowles (2009) FDI Flow Volatility and ASEAN Members: An Exploratory Approach. Economics Working Paper 6, University of Utah.

Gersbach, Hans, and Armin Schmutzler (2011) Foreign Direct Investment and R\&D-Offshoring. Oxford Economic Papers, 63, 134-57.

Glass, Amy (2010) Imitation as a Stepping Stone to Innovation. Texas A\&M.

Haaland, Jan I., and Ian Wooton (2001) Multinational Firms: Easy Come, Easy Go? Discussion Paper 2660, London: CEPR.

Horstmann, Ignatius J. and James R. Markusen (1987) Strategic Investments and the Development of Multinationals. International Economic Review, 28, 109-21.

Horstmann, Ignatius J. and James R. Markusen (1996) Exploring New Markets: Direct Investment, Contractual Relations and the Multinational Enterprise. International Economic Review, 37, 1-19. 
Iacopetta, Maurizio (2011) Formal Education and Public Knowledge. Journal of Economic Dynamics and Control. 35, 676-93.

Jones, Charles (2005) Growth and Ideas. In P.Aghion and S.Durlauf (ed.) Handbook of Economic Growth, 1063-111, Amsterdam: Elsevier.

Kam, Andrew (2013) International Production Networks and Host Country Productivity: Evidence from Malaysia. Asian-Pacific Economic Literature, 27, 127-46.

Kharas, Homi, Albert Zeufack, and Hamdan Majeed (2010) Cities, People 83 the Economy: A Study on Positioning Penang, Kuala Lumpur: Khazanah Nasional.

Kottaridi, Constantina and Thanasis Stengos (2010) Foreign Direct Investment, Human Capital and Non-linearities in Economic Growth. Journal of Macroeconomics, $32,858-71$.

Lim, King Yoong (2015) Is Innovation Shortfall in Malaysia a Structural Issue? Evidence from PICS on FDI, Ownership Mode, and Investment Climate. unpublished, University of Manchester.

Markusen, James R (1995) The Boundaries of Multinational Enterprises and the Theory of International Trade. Journal of Economic Perspectives, 9, 169-89.

Markusen, James R (1998) Multinational Firms, Location and Trade. World Economy, 21, 733-56.

Markusen, James R. and Keith E. Maskus (2002) Discriminating among Alternative Theories of the Multinational Enterprise. Review of International Economics, 10, 694707.

Markusen, James R. and Natalia Trofimenko (2009) Teaching Locals New Tricks: Foreign Experts as a Channel of Knowledge Transfers. Journal of Development Economics, 88, 120-31.

Markusen, James R., and Anthony J. Venables (1999) Foreign Direct Investment as a Catalyst for Industrial Development. European Economic Review, 43, 335-56. 
Melitz, Marc J (2003) The Impact of Trade on Intra-Industry Reallocations and Aggregate Industry Productivity. Econometrica, 71, 1695-725.

Nelson, Richard R. and Howard Pack (1999) The Asian Miracle and Modern Growth Theory. Economic Journal, 109, 416-36.

Olney,William W (2013) A Race to the Bottom? Employment Protection and Foreign Direct Investment. Journal of International Economics, 91, 191-203.

Romer, Paul M (1990) Endogenous Technological Change. Journal of Political Economy, S71-102.

Saggi, Kamal (2002) Trade, Foreign Direct Investment, and International Technology Transfer: A Survey. World Bank Research Observer, 17, 191-235.

Sander, Frederico Gil and Marek Hanusch (2012) Malaysia Economic Monitor: Modern Jobs. Washington DC: World Bank.

Sequeira, Tiago (2011) R\&D spillovers in an endogenous growth model with physical capital, human capital, and varieties. Macroeconomic Dynamics, 15, 223-39.

Trimborn, Timo, Karl-J Koch and Thomas Steger (2008) Multidimensional Transitional Dynamics: A Simple Numerical Procedure. Macroeconomic Dynamics, 12, 301-19.

Yusuf, Shahid and Kaoru Nabeshima (2009) Tiger Economies Under Threat : A Comparative Analysis of Malaysia's Industrial Prospects, World Bank.

Zeufack, Albert and King Yoong Lim (2013) Can Malaysia Achieve Innovation-led Growth? Kuala Lumpur: Khazanah Nasional. 


\section{Tables and Figures}

Table 1

Calibrated Parameter Values: Benchmark (for Host Economy)

\begin{tabular}{ccl}
\hline \hline Parameter & Value & \multicolumn{1}{c}{ Description } \\
\hline \hline Households & & \\
$\rho$ & 0.04 & Annual discount rate \\
$\sigma$ & 0.27 & Elasticity of intertemporal substitution \\
$\xi$ & 0.0173 & Population growth rate \\
$\Gamma$ & 0.9 & Productivity parameter (efficiency of skills acquisition) \\
$\chi$ & 0.25 & Skills acquisition cost (in proportion of skilled wage) \\
Final Output & 2.001 & Pareto index, breadth of ability distribution in host economy \\
$\alpha$ & 0.3 & Elasticity with respect to private capital \\
$\beta^{U}$ & 0.15 & Elasticity with respect to unskilled labour \\
$\beta^{S}$ & 0.25 & Elasticity with respect to skilled labour \\
$\gamma$ & 0.3 & Elasticity wrt composite intermediate input \\
$v$ & 0.57 & Share of basic input in composite intermediate input \\
$\Lambda^{Y}$ & 0.05 & Cost mark-up due to labour market distortions \\
$\delta$ & 0.068 & Rate of depreciation, private capital \\
Intermediate goods & \\
$\eta$ & 0.39 & Substitution parameter for production, intermediate goods \\
\hline
\end{tabular}

Table 2

Calibrated Parameter Values: Benchmark (for Host Economy, continue)

\begin{tabular}{|c|c|c|c|}
\hline \multirow{2}{*}{\multicolumn{2}{|c|}{$\begin{array}{c}\text { Parameter } \\
\text { Imitation sector }\end{array}$}} & Value & Description \\
\hline & & & \\
\hline \multicolumn{2}{|l|}{$\psi_{1}^{I}$} & 0.35 & Elasticity wrt number of foreign experts in Horizontal mode \\
\hline \multicolumn{2}{|l|}{$\psi_{2}^{I}$} & -0.3 & Externality, Vertical MNCs and innovative blueprint \\
\hline \multicolumn{2}{|l|}{$\Lambda^{I}$} & 0.1 & Cost mark-up due to labour market distortions \\
\hline \multicolumn{4}{|c|}{ Innovation sector } \\
\hline \multicolumn{2}{|l|}{$\psi_{1}^{R}$} & 0.4 & Elasticity wrt number of foreign experts in Vertical mode \\
\hline \multicolumn{2}{|l|}{$\psi_{2}^{R}$} & 9.5 & Stepping stone effect, from stock of imitative goods \\
\hline \multicolumn{2}{|l|}{$\Lambda^{R}$} & 0.2 & Cost mark-up due to labour market distortions \\
\hline \multicolumn{4}{|c|}{ Government } \\
\hline \multicolumn{2}{|l|}{$\tau$} & 0.25 & Effective tax rate on final output \\
\hline \multicolumn{4}{|c|}{$\begin{array}{l}\text { Table } 3 \\
\text { Calibrated Parameter Values: Benchmark (for Foreign sector) }\end{array}$} \\
\hline arameter & Value & & Description \\
\hline$\sigma^{F}$ & 2.0 & Elas & sticity of foreign preference, between varieties \\
\hline$\theta^{F}$ & 1.64 & Elas & sticity of foreign preference, across varieties \\
\hline$P_{0}$ & 1.0 & Bas & seline price, Platform FDI's investment \\
\hline$L I$ & 0.7456 & 6 Lerr & mer Index, proxy for pricing competition \\
\hline$F_{0}$ & 0.2733 & 3 Bas & sic doing-business cost incurred on foreign experts \\
\hline$F_{1}$ & 0.33 & Add & ditional cost incurred on Horizontal MNC \\
\hline$F_{2}$ & 0.40 & Add & ditional cost incurred on Vertical MNC \\
\hline$\tilde{a}$ & 9.55 & Con & nstant value linking productivity to ability \\
\hline$\phi$ & -1.0 & Asy & ymmetric cost parameter, Vertical MNC-specific \\
\hline$\omega_{k}$ & 1.0 & Shat & ape parameter, Weibull function \\
\hline$\omega_{\lambda}$ & 2.0 & Slop & pe parameter, spread of Weibull distribution \\
\hline$w_{m}$ & 3.6 & Con & instant, feedback to foreign preference \\
\hline
\end{tabular}


Table 4

Individual Policies: Steady-state Effects (Absolute deviations from baseline)

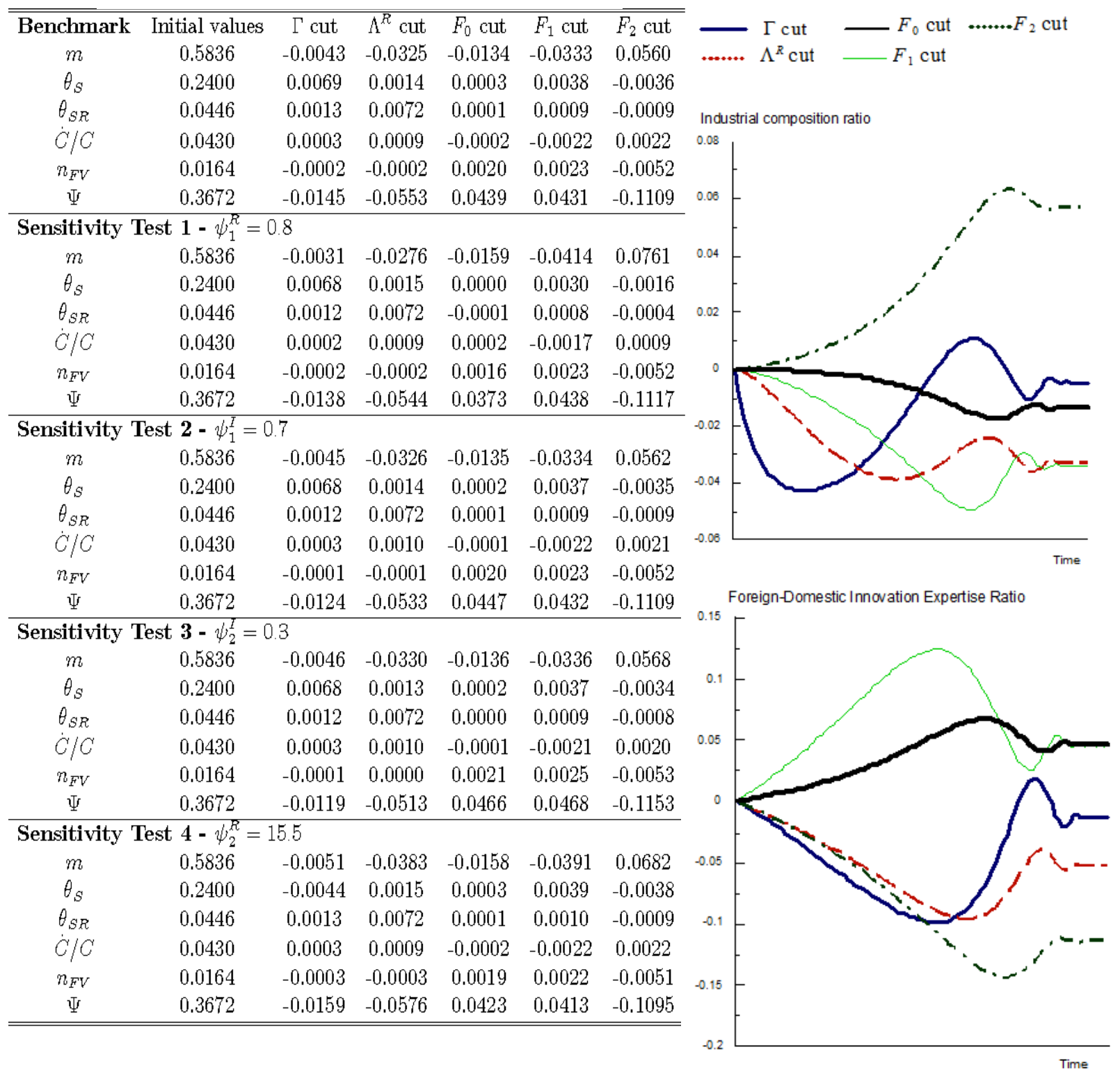

Figure 1

Individual Policies

(Absolute deviations from baseline)

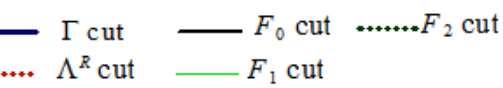

ndustrial composition ratio

0.06
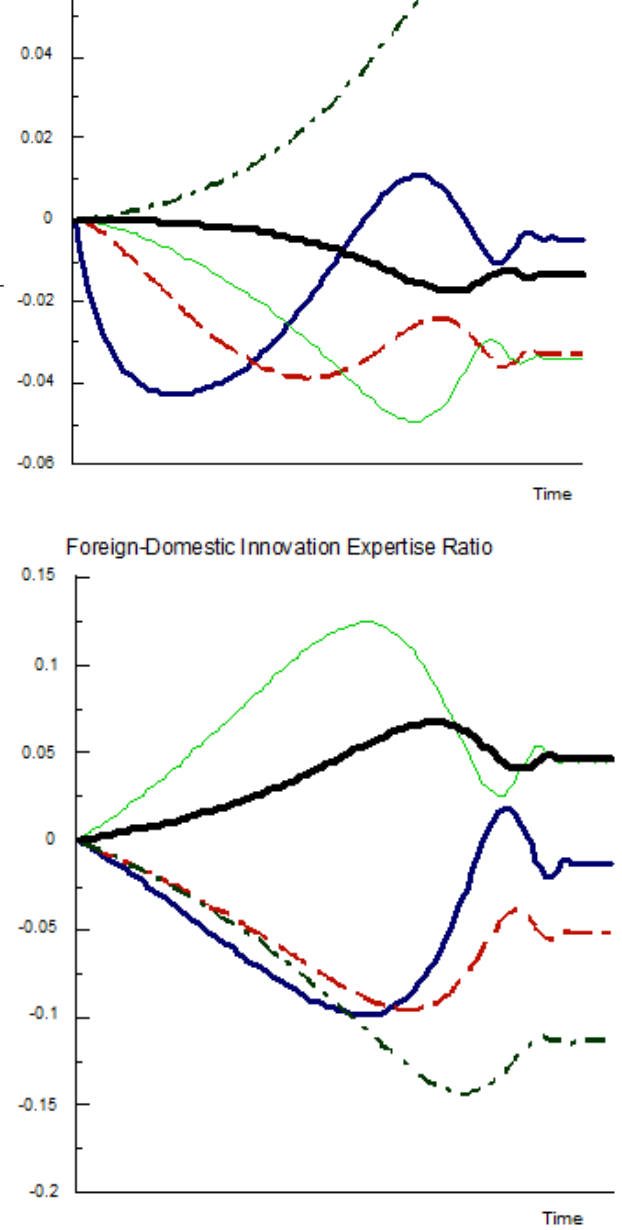
Table 5

FDI-promoting Policies: Steady-state Effects for Different Initial Level of Basic Doing-Business Cost $\left(F_{0}\right)$

\begin{tabular}{|c|ccc|cccc|ccc|}
\hline & \multicolumn{3}{|c|}{$\mathbf{F}_{\mathbf{0}}$ shock } & \multicolumn{3}{c|}{$\mathbf{F}_{\mathbf{1}}$ shock } & \multicolumn{3}{c|}{ F $_{\mathbf{2}}$ shock } \\
\cline { 2 - 11 } Initial $\mathbf{F}_{0}$ & $m_{t}$ & $\Psi_{t}$ & $\dot{Y}_{t} / Y_{t}$ & $m_{t}$ & $\Psi_{t}$ & $\dot{Y}_{t} / Y_{t}$ & $m_{t}$ & $\Psi_{t}$ & $\dot{Y}_{t} / Y_{t}$ \\
\cline { 2 - 10 } $\mathbf{0 . 2 0}$ & Absolution deviation from baseline & Absolution deviation from baseline & Absolution deviation from baseline \\
\cline { 2 - 11 } $\mathbf{0 . 2 5}$ & -0.01201 & 0.03890 & -0.00059 & -0.03477 & 0.03901 & -0.00102 & 0.05360 & -0.10279 & 0.00322 \\
$\mathbf{0 . 3 0}$ & -0.01306 & 0.04603 & -0.00029 & -0.03323 & 0.04654 & -0.00197 & 0.05573 & -0.11939 & 0.00242 \\
$\mathbf{0 . 3 5}$ & -0.01413 & 0.05153 & 0.00002 & -0.03400 & 0.05224 & -0.00198 & 0.05760 & -0.12096 & 0.00165 \\
$\mathbf{0 . 4 0}$ & -0.01499 & 0.05240 & 0.00030 & -0.03478 & 0.05457 & -0.00170 & 0.05902 & -0.11267 & 0.00094 \\
$\mathbf{0 . 4 5}$ & -0.01573 & 0.05007 & 0.00053 & -0.03535 & 0.05311 & -0.00141 & 0.06016 & -0.09951 & 0.00031 \\
$\mathbf{0 . 5 0}$ & -0.01634 & 0.04588 & 0.00074 & -0.03576 & 0.04928 & -0.00115 & 0.06028 & -0.09051 & -0.00003 \\
\hline
\end{tabular}

Note: For $F_{2}$ shock, the model solves only up to $F_{0}=0.431$, which produce the results highlighted in red. 
Figure 2: Permanent Cut of $F_{0}$ by the same percent as Benchmark 0.03 Cut (Absolute deviations from baseline)

$\longrightarrow F_{0}=0.2733$

$$
F_{0}=0.2433
$$

Positive $\psi_{2}^{I}$
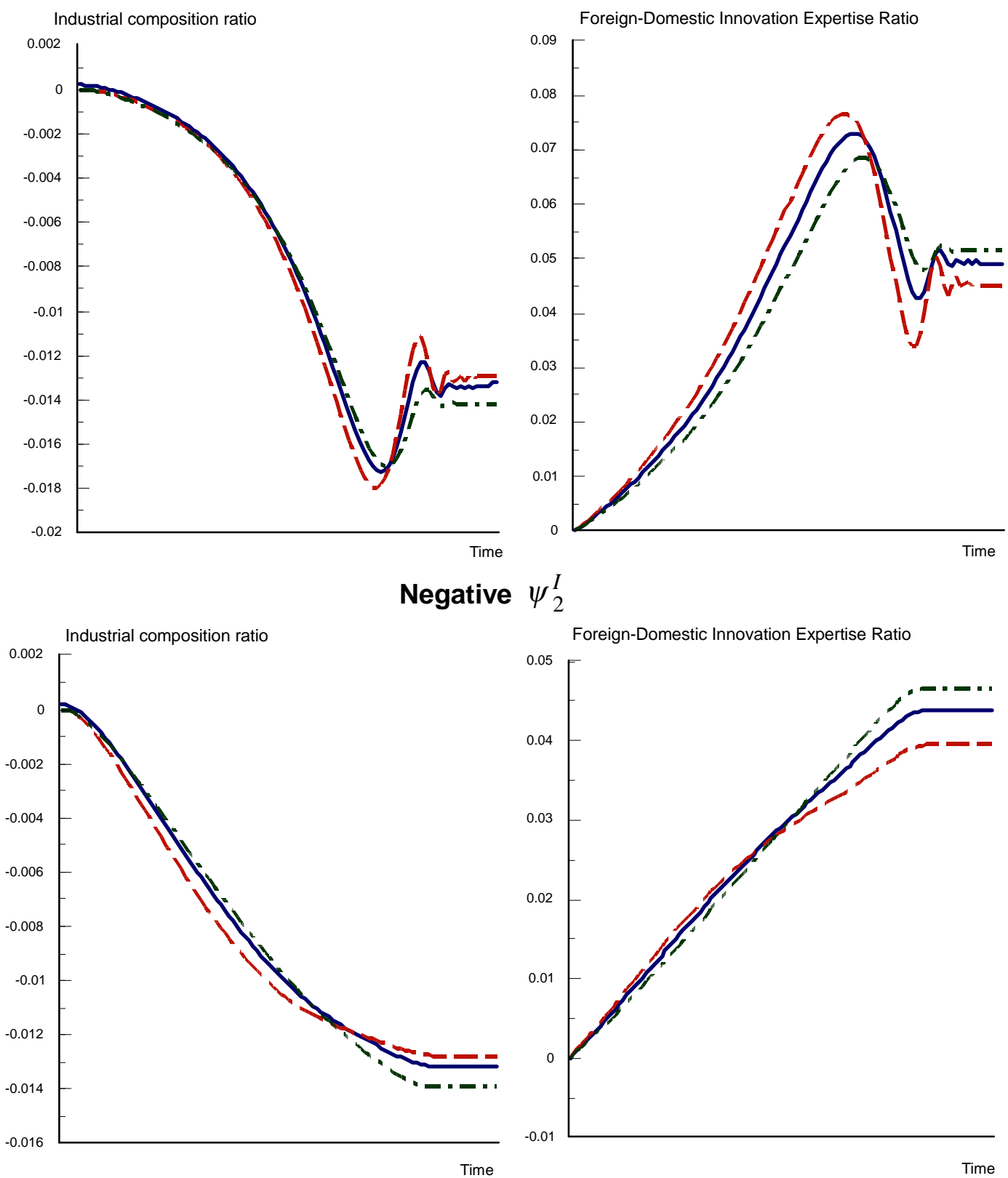
Figure 3: Permanent Cut of $F_{1}$ by the same percent as Benchmark 0.03 Cut (Absolute deviations from baseline)

$-F_{1}=0.33$

$\cdots F_{1}=0.30$

$\cdots F_{1}=0.36$
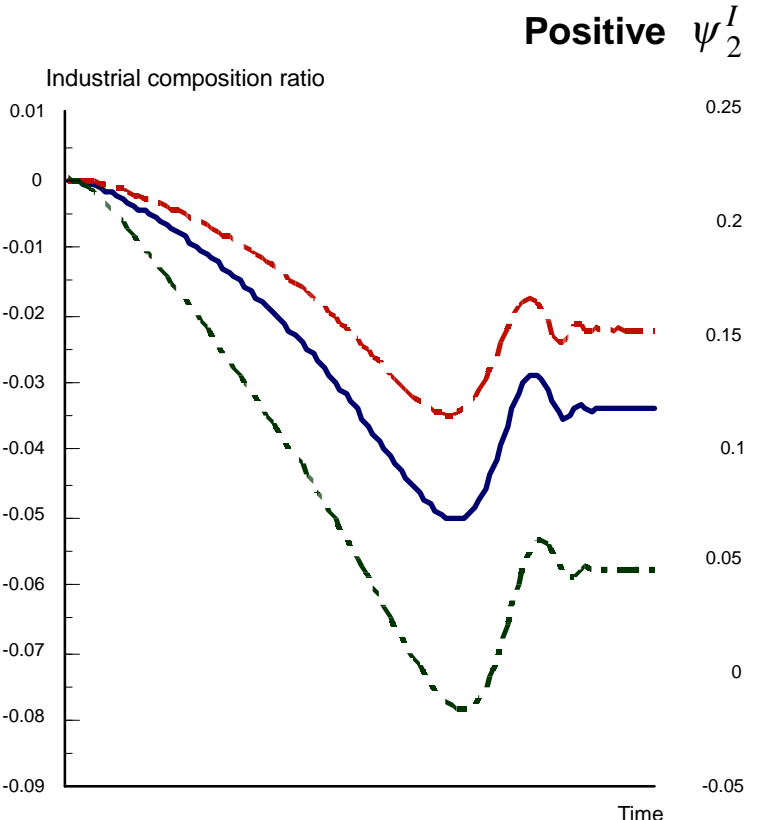

$\psi_{2}^{I}$
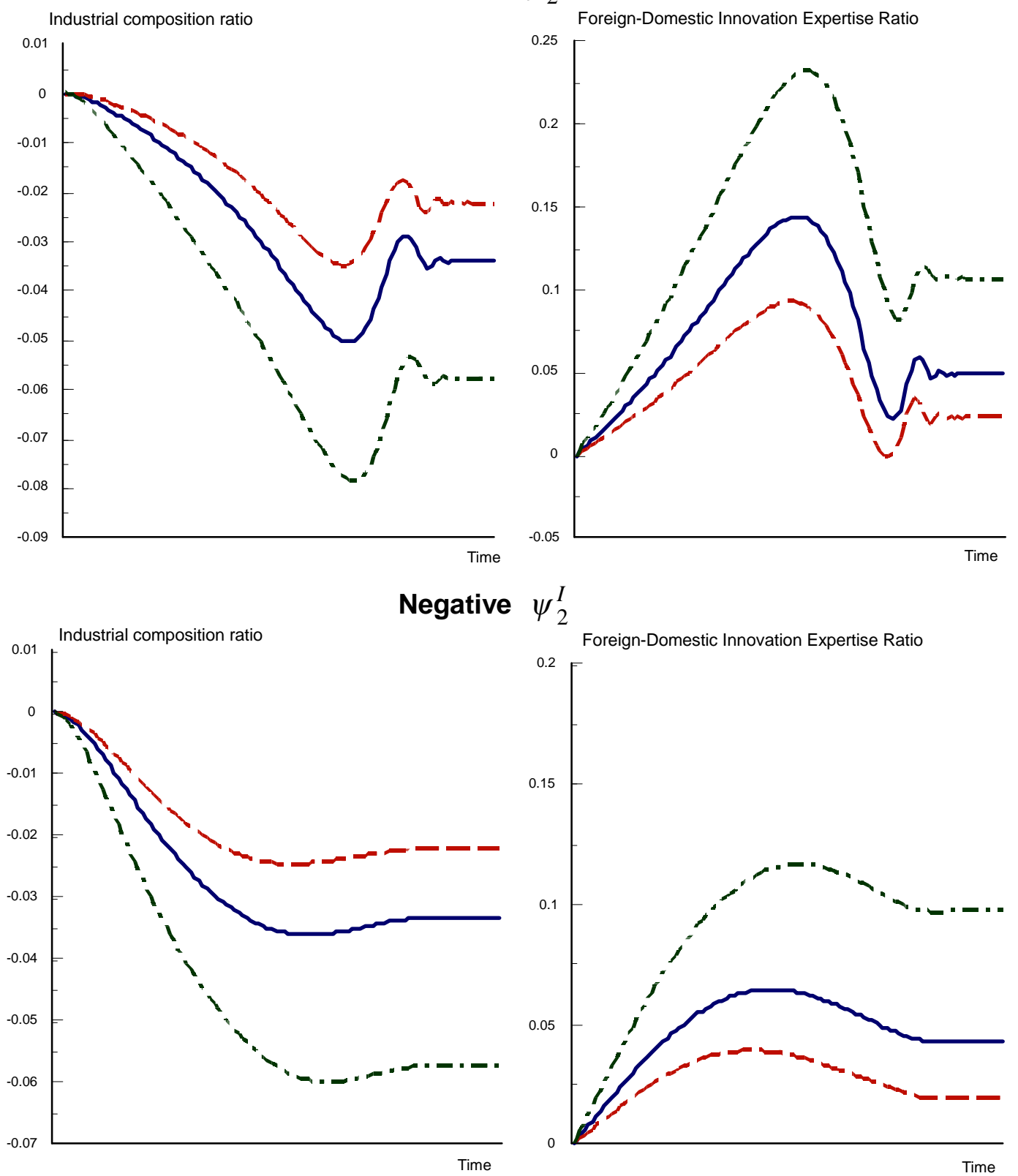
Figure 4: Permanent Cut of $F_{2}$ by the same percent as Benchmark 0.03 Cut, (Absolute deviations from baseline)

$-F_{2}=0.40$

$\ldots F_{2}=0.37$

$F_{2}=0.43$

Positive $\psi_{2}^{I}$
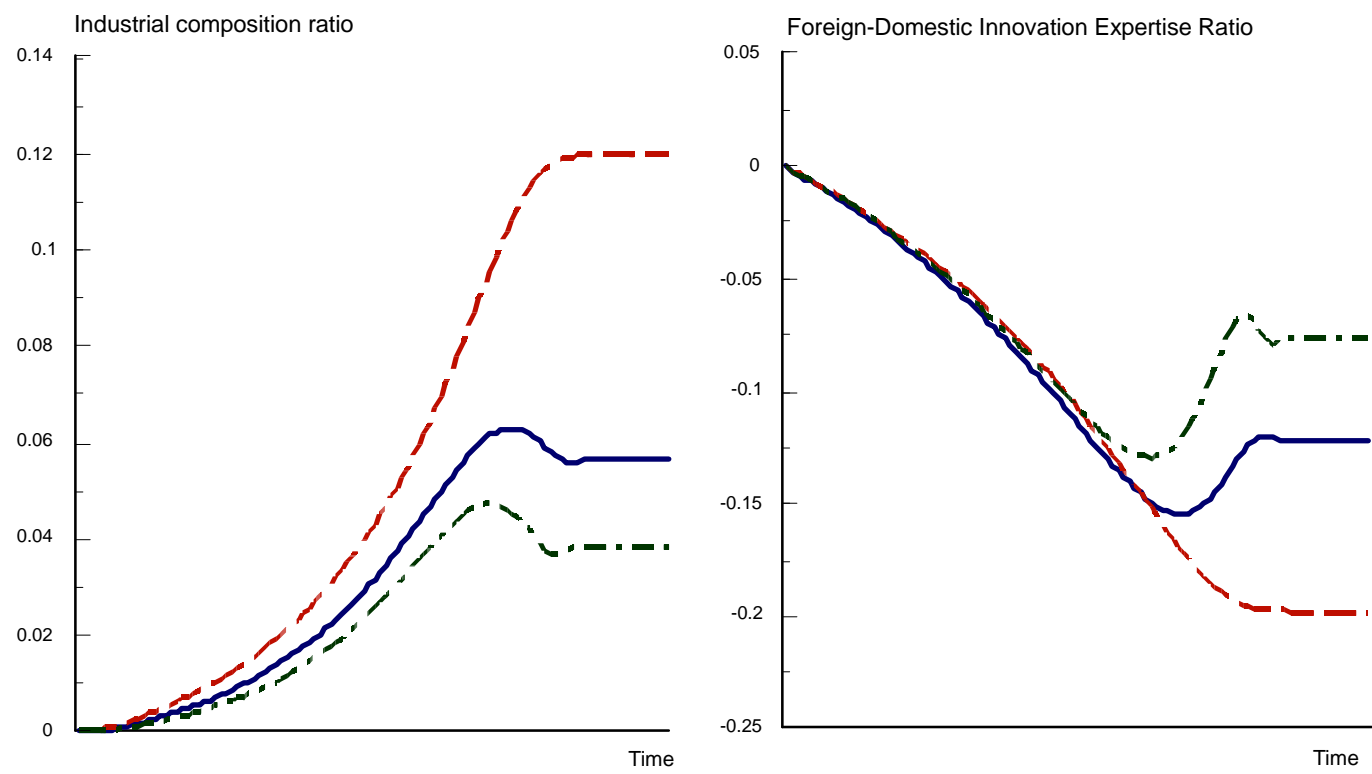

Negative $\psi_{2}^{I}$

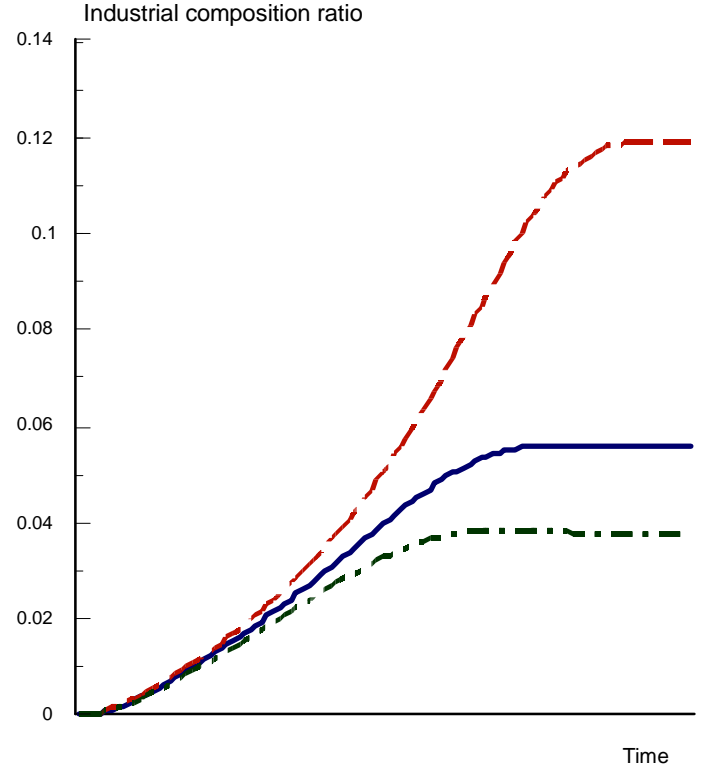

Foreign-Domestic Innovation Expertise Ratio

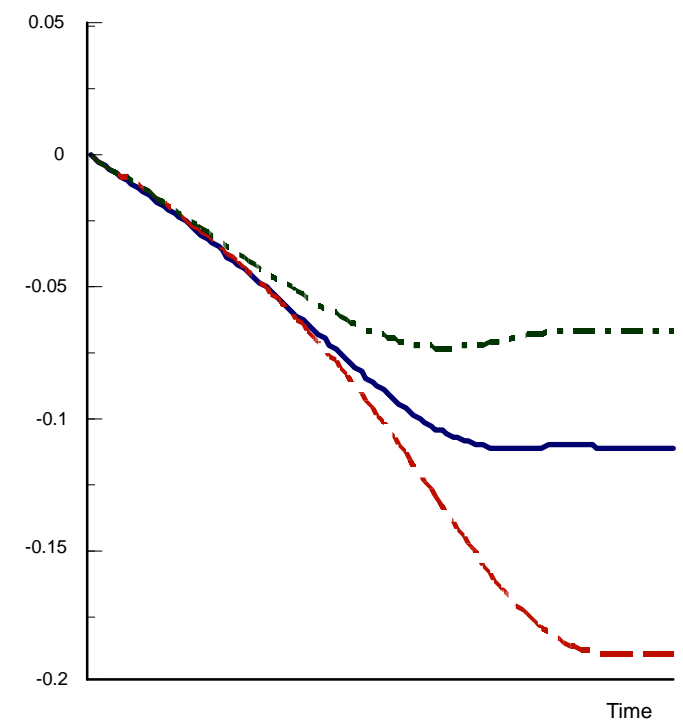


Figure 5

Composite Programmes:

Table 6

(Absolute deviations from baseline)

Composite Programmes: Steady-state Effects

- Composite A

(Absolute deviations from baseline)

....... Composite B

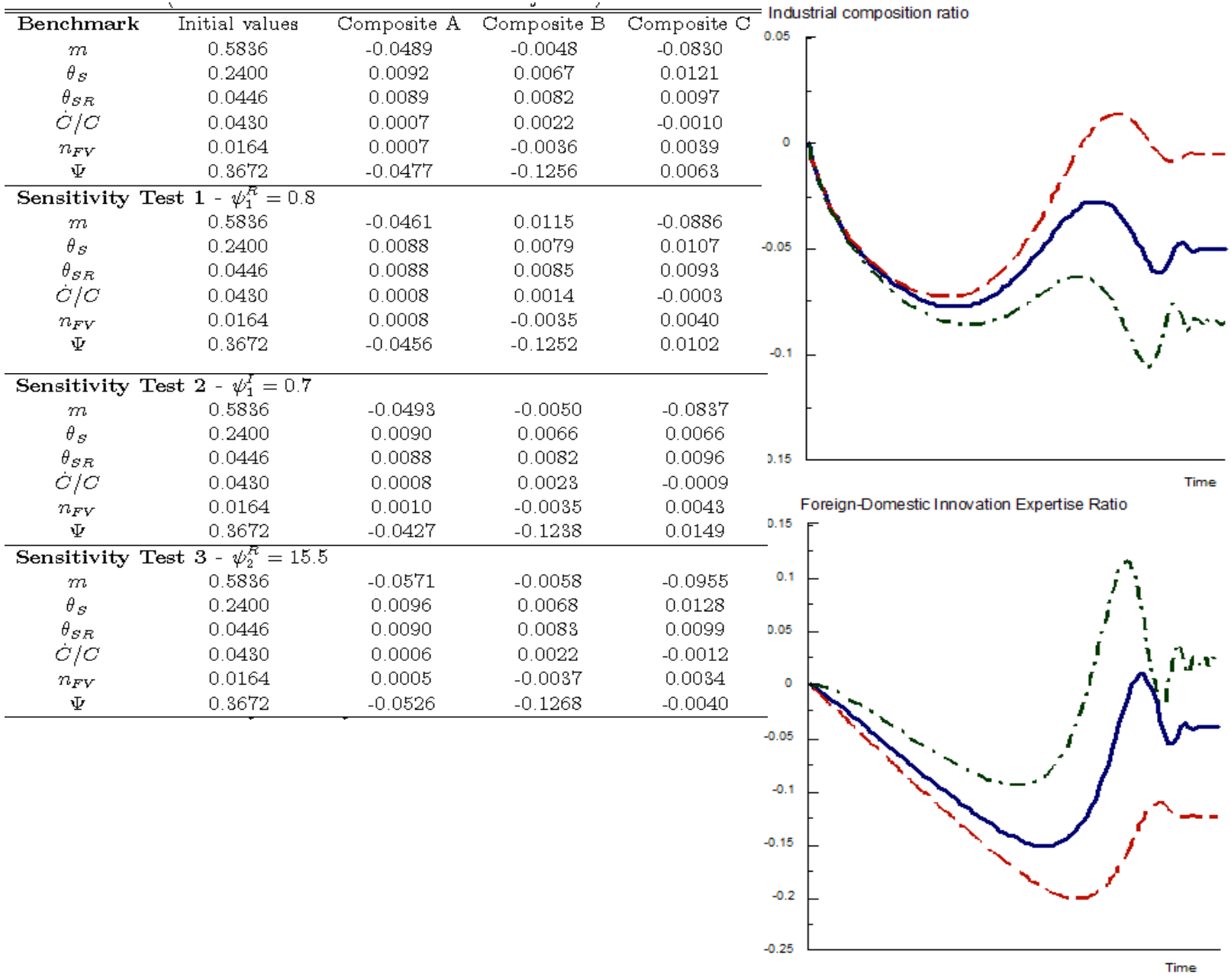


Figure 6: Composite Programme A - Industrial composition ratio (Absolute deviations from baseline)

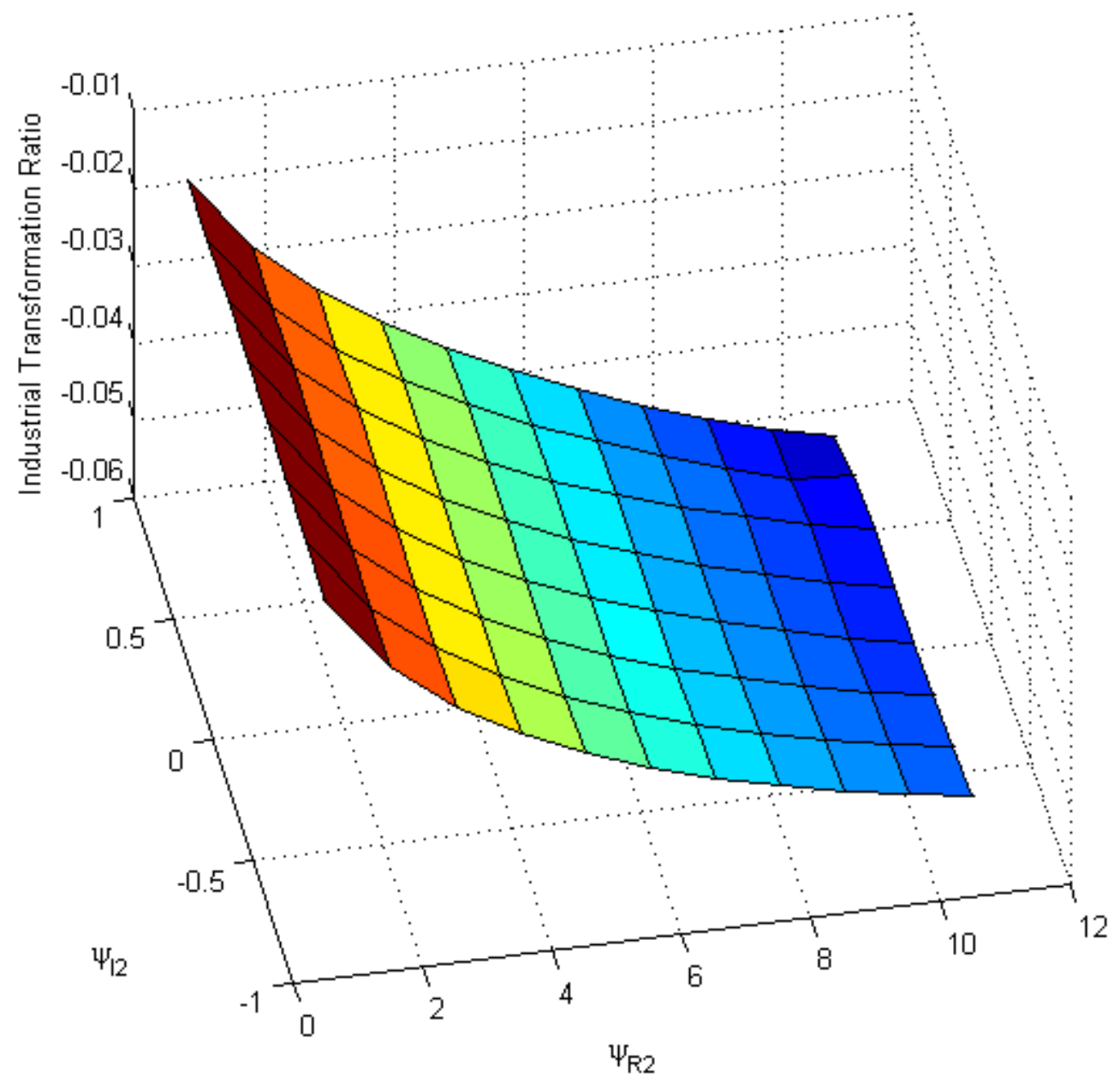


Table 7

Sensitivity Analysis: Endogenous $v$ with Generalised Logistic Curve

Composite Programmes: Steady-state Effects (Abs deviation)

\begin{tabular}{|c|c|c|c|c|c|c|c|c|}
\hline & Initial values & Composite A & Composite B & Composite C & & Composite A & Composite B & Composite C \\
\hline \multicolumn{6}{|c|}{$100 \%$ diffusion rate, $\zeta=1.0$} & \multicolumn{3}{|c|}{$400 \%$ diffusion rate, $\zeta=4.0$} \\
\hline$m$ & 0.5836 & -0.0535 & -0.0054 & -0.0902 & $m$ & -0.0709 & -0.0076 & -0.1141 \\
\hline$\theta_{S}$ & 0.2400 & 0.0105 & 0.0068 & 0.0143 & $\theta_{S}$ & 0.0165 & 0.0075 & 0.0238 \\
\hline$\theta_{S R}$ & 0.0446 & 0.0101 & 0.0083 & 0.0118 & $\theta_{S R}$ & 0.0155 & 0.0089 & 0.0205 \\
\hline$C / C$ & 0.0430 & 0.0009 & 0.0022 & -0.0007 & $C / C$ & 0.0017 & 0.0023 & 0.0008 \\
\hline$\Psi$ & 0.3672 & -0.0566 & -0.1262 & -0.0112 & $\Psi$ & -0.0931 & -0.1294 & -0.0764 \\
\hline$v$ & 0.5700 & -0.0097 & -0.0010 & -0.0164 & $v$ & -0.0532 & -0.0055 & -0.0859 \\
\hline \multicolumn{6}{|c|}{$200 \%$ diffusion rate, $\zeta=2.0$} & \multicolumn{3}{|c|}{$500 \%$ diffusion rate, $\zeta=5.0$} \\
\hline$m$ & 0.5836 & -0.0585 & -0.0060 & -0.0978 & $m$ & -0.0780 & -0.0087 & -0.1217 \\
\hline$\theta_{S}$ & 0.2400 & 0.0121 & 0.0070 & 0.0169 & $\theta_{S}$ & 0.0195 & 0.0078 & 0.0280 \\
\hline$\theta_{S R}$ & 0.0446 & 0.0116 & 0.0085 & 0.0142 & $\theta_{S R}$ & 0.0182 & 0.0092 & 0.0243 \\
\hline$C / C$ & 0.0430 & 0.0011 & 0.0022 & -0.0003 & $C / C$ & 0.0021 & 0.0023 & 0.0015 \\
\hline$\Psi$ & 0.3672 & -0.0670 & -0.1271 & -0.0310 & $\Psi$ & -0.1090 & -0.1309 & -0.1010 \\
\hline$v$ & 0.5700 & -0.0215 & -0.0021 & -0.0361 & $v$ & -0.0739 & -0.0080 & -0.1153 \\
\hline \multicolumn{9}{|c|}{$300 \%$ diffusion rate, $\zeta=3.0$} \\
\hline$m$ & 0.5836 & -0.0643 & -0.0067 & -0.1059 & & & & \\
\hline$\theta_{S}$ & 0.2400 & 0.0141 & 0.0072 & 0.0200 & & & & \\
\hline$\theta_{S R}$ & 0.0446 & 0.0134 & 0.0086 & 0.0171 & & & & \\
\hline$C / C$ & 0.0430 & 0.0013 & 0.0023 & 0.0002 & & & & \\
\hline$\Psi$ & 0.3672 & -0.0791 & -0.1280 & -0.0528 & & & & \\
\hline$v$ & 0.5700 & -0.0358 & -0.0035 & -0.0592 & & & & \\
\hline
\end{tabular}

Table 8

Policy Complementarities - Composite Programme A

(Absolute deviations)

\begin{tabular}{lccccc}
\hline \hline & $m$ & $\theta_{S}$ & $\theta_{S R}$ & $C / C$ & $\Psi$ \\
\hline Sum of Parts: & & & & & \\
$\Gamma$ cut & -0.0043 & 0.0069 & 0.0013 & 0.0003 & -0.0145 \\
$\Lambda^{R}$ cut & -0.0325 & 0.0014 & 0.0072 & 0.0009 & -0.0553 \\
$F_{0}$ cut & -0.0134 & 0.0003 & 0.0001 & -0.0002 & 0.0439 \\
$F_{1}$ cut & -0.0333 & 0.0038 & 0.0009 & -0.0022 & 0.0431 \\
$F_{2}$ cut & 0.0560 & -0.0036 & -0.0009 & 0.0022 & -0.1109 \\
\hline Aggregate effects & $\mathbf{- 0 . 0 2 7 5}$ & $\mathbf{0 . 0 0 8 7}$ & $\mathbf{0 . 0 0 8 6}$ & $\mathbf{0 . 0 0 1 1}$ & $\mathbf{- 0 . 0 9 3 7}$ \\
\hline & & & & & \\
Composite A (fixed $v$ ) & $\mathbf{- 0 . 0 4 8 9}$ & $\mathbf{0 . 0 0 9 2}$ & $\mathbf{0 . 0 0 8 9}$ & $\mathbf{0 . 0 0 0 7}$ & $\mathbf{- 0 . 0 4 7 7}$
\end{tabular}

Composite A (endogenous $v$ )

\begin{tabular}{|c|c|c|c|c|c|}
\hline$-\zeta=1.0$ & -0.0535 & 0.0105 & 0.0101 & 0.0009 & -0.0566 \\
\hline$-\zeta=2.0$ & -0.0585 & 0.0121 & 0.0116 & 0.0011 & -0.0670 \\
\hline$-\zeta=3.0$ & -0.0643 & 0.0141 & 0.0134 & 0.0013 & -0.0791 \\
\hline$-\zeta=4.0$ & -0.0709 & 0.0165 & 0.0155 & 0.0017 & -0.0931 \\
\hline$-\zeta=5.0$ & -0.0780 & 0.0195 & 0.0182 & 0.0021 & -0.1090 \\
\hline
\end{tabular}

